\title{
MAN'S CONQUEST OF ENERGY: ITS ECOLOGICAL \\ AND HUMAN CONSEQUENCES
}

\author{
M. King Hubbert
}

Research Geophysicist, U. S. Geological Survey, Department of the Interior

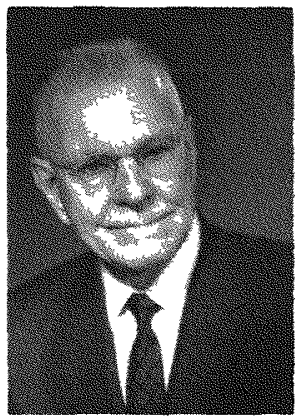

Dr. Hubbert received the B.S., M.S., and Ph. D. degrees in geology and physics from the University of Chicago. In addition to teaching at Columbia University and Stanford University, he has conducted and directed research at the Shell Oil Company in Texas and with the U. S. Geological Survey. He is a member of the National Academy of Sciences and a Fellow of the American Academy of Arts and Sciences and has served as Chairman of the Division of Earth Sciences of the National Research Council, as a member of the NAS-NRC committee advisory to the AEC on land disposal of atomic wastes, and as a member of the NAS Committee on Natural Resources advisory to President John F. Kennedy and author of its report on energy resources. He is the author of The Theory of Groundwater Motion and Structural Geology in addition to over 60 articles in scientific journals.

The topic I will discuss is man's progressive conquest of energy during the last million years and its consequences to the earth's plant and animal ecology and in particular to man himself. However, to appreciate our present situation and our prospects for the future, we must take account of the geological span of time in which our species has evolved and look at a longer period of human history than that to which we are accustomed.

The time scale of geologic history is shown in Fig. 1. The upper horizontal line is a graphical representation of the entire history of the earth. Recent radioactive datings 


\section{DISCLAIMER}

This report was prepared as an account of work sponsored by an agency of the United States Government. Neither the United States Government nor any agency Thereof, nor any of their employees, makes any warranty, express or implied, or assumes any legal liability or responsibility for the accuracy, completeness, or usefulness of any information, apparatus, product, or process disclosed, or represents that its use would not infringe privately owned rights. Reference herein to any specific commercial product, process, or service by trade name, trademark, manufacturer, or otherwise does not necessarily constitute or imply its endorsement, recommendation, or favoring by the United States Government or any agency thereof. The views and opinions of authors expressed herein do not necessarily state or reflect those of the United States Government or any agency thereof. 


\section{DISCLAIMER}

Portions of this document may be illegible in electronic image products. Images are produced from the best available original document. 

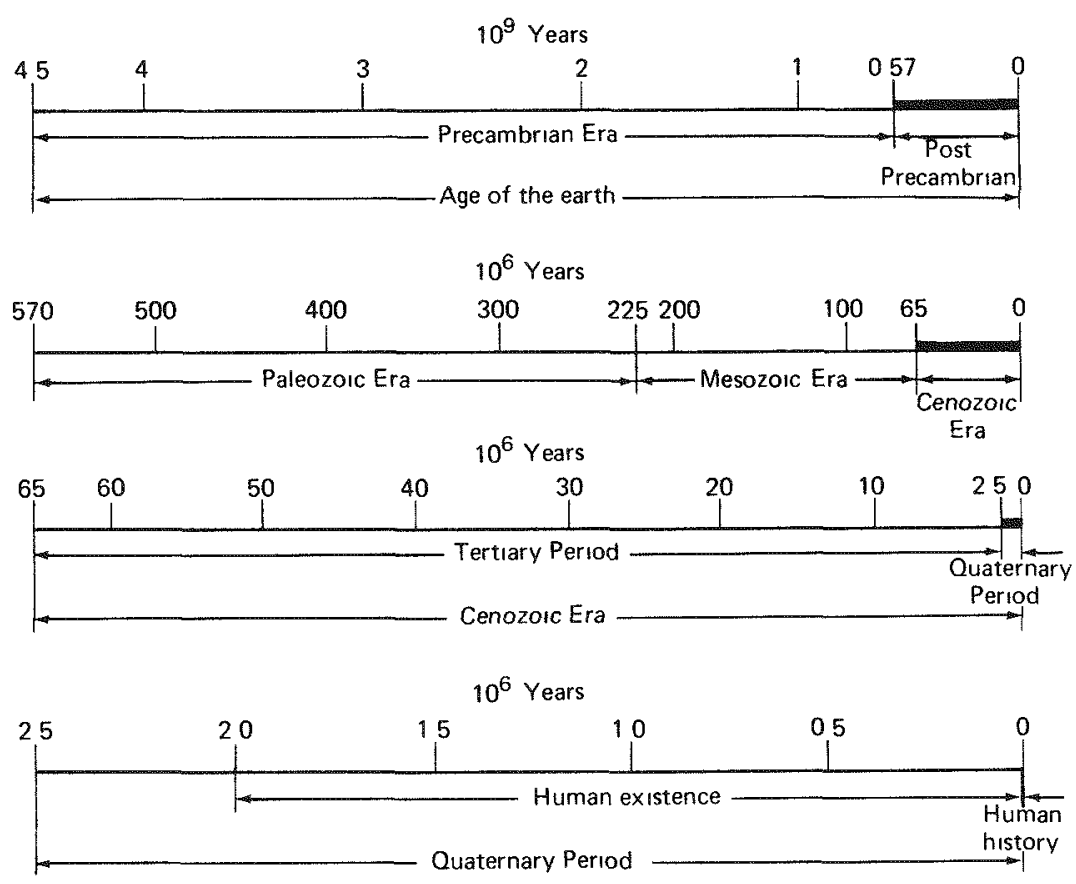

Fig. 1 Geologic time.

of meteontes are consistent in indicating that the catastrophic astronomical event that produced the solar system (including the earth) must have occurred about 4.5 billon years ago. On this linear chart, the total history of the earth is divided into two parts that from the earth's origin 45 billion years ago to about 570 millon years ago, the Precambrian Era of geological history, and the subsequent 570 millon years, comprising the Paleozorc, Mesozolc, and Cenozorc Eras

In the Precambrian Era geological history becomes increasingly less well known the farther back we go. In fact, the oldest known terrestrial rock is radioactively dated at only about 3.7 billion years. The oldest known fossils of primitive organisms are dated at about 3.2 billion years. Thus, although life must have orignated earlier than this, the fossil record is scanty prior to the beginning of the Cambrian Period. However, during the Precambrian Era many of the earth's major ores of industrial metals - iron, copper, nickel, and the like-were deposited. Since the beginning of the Paleozorc Era, abundant fossils have been preserved in the succeeding sedimentary strata, affording us a reasonably continuous record of the evolution of the earth's organisms.

The second bar of Fig 1 represents an enlargement of the last 570 million years It is divided into three successive geologic eras. The Paleozorc Era, extending from the beginning of the Cambrian Period to the end of the Permian Period dbout 225 million years ago, the Mesozoic Era from 225 to about 65 million years ago, and finally the 
Cenozolc Era, extending to the present The final two linear scales represent an enlargement of the Cenozorc Era and show the period of the rise of man

For the corresponding highlights in the evolution of organisms, all of the phyla of the animal kingdom except the vertebrates were already in existence by the beginning of the Cambrian Period By Devonian time (395-345 million years ago), large fishes had appeared Then, by Pennsylvanian time (about 320-280 millon years ago), amphibians began to appear During Permian time (280-225 millon years ago), these evolved into fully land dwelling reptiles which, during the Mesozorc Era, the so-called Age of Reptiles, proliferated into the huge dinosaurs and associated reptiles Finally, during the following 65 milion years of the Cenozolc Era, we witness the emergence and progressive evolution of the mammals including, during the last 2 million years, the human species

In parallel with the evolution of animals, plants first emerged from an aqueous environment and blanketed the land surface in Silurian time (about 440-395 million years ago) Then, by Pennsylvanian tıme (about 320-280 million years ago), formerly known as the "Carbonfferous," there occurred the dense forests whose plant remains produced the world's first widespread deposits of coal, including those of eastern North America, Gredt Britain, Holland, Belgium, and France

In the last million or two years, the human species rose to dominance Since our species did not originate suddenly, it cannot be sald of dny specific time that "man began here "However, from the recent excavdtions by Dr L S B and Mary Leakey in the Olduvar Gorge in Tanzania, Africa, it appears that near relatives, if not direct ancestors, of the present human species were already walking upright and using primitive stone tools as long ago as 17 million years Subsequently, there must have occurred the succession of unprecedented activities, such as fire bulding, domestica tion of animals and plants, and the smelting of metals, which led finally to the proliferation of activities characterizing the world's present industrialized societies

It is especidly significant that most of this industrial evolution has required only the last century of the entire span of geologic history, yet it represents one of the major geological events of the earth's history

\section{TERRESTRIAL ENERGY FLUX}

One of the most general views possible concerning events that occur on the earth is based on the recognition that the ensemble of such events-biological as well as inorganic - consists in the last analysis of a circulation of the edrth's material constituents and a degradation of energy From this point of view we may regard the earth as being composed of various dmounts of the 92 naturally occurring chemicd elements, which, with the exception of a tew isotopes with an abundance of but a few parts per million, obey the laws of conservation and nontransmutability of classical chemistry Into and out of the earth's surface environment there occurs a continuous flux and degradation of energy Consequently the earth's surface materials undergo either continuous or intermittent circulation 


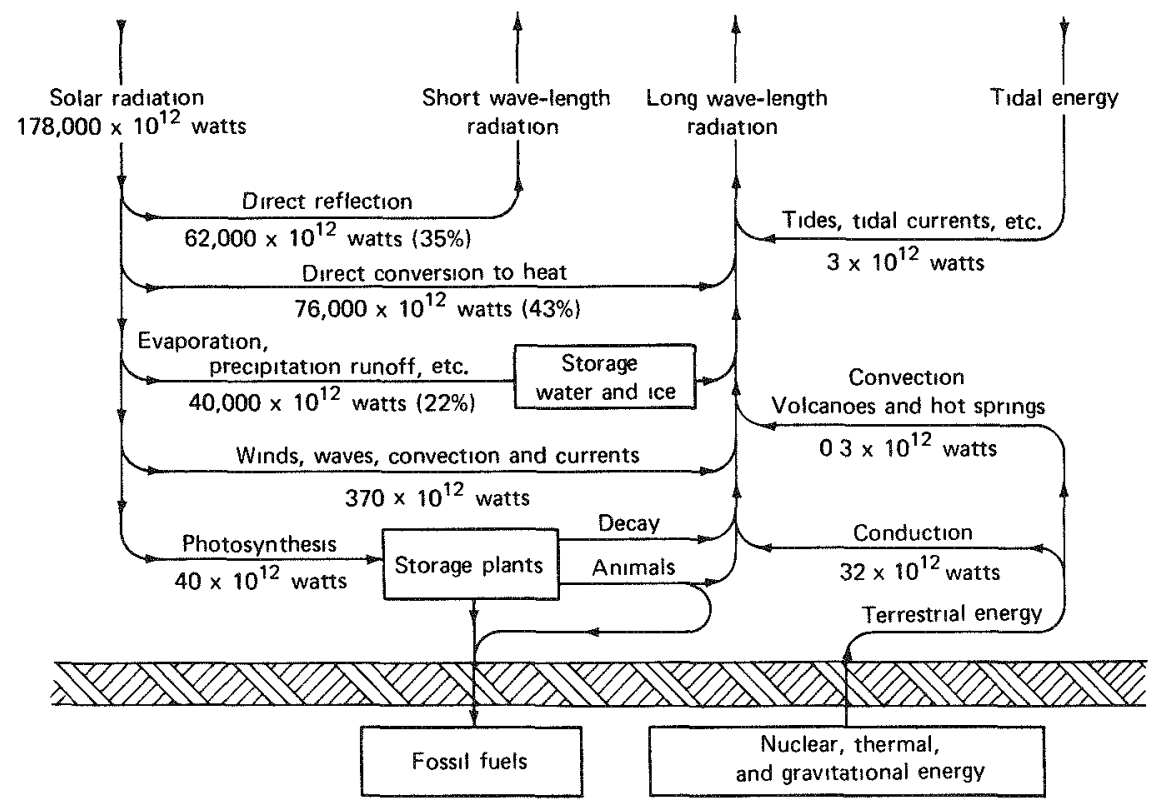

Fig. 2 Energy llow sheet for the earth. ${ }^{1}$

The nature of this energy flux is shown in Fig. 2 The significant energy influxes are from three sources (1) solar radiation amounting to about $178,000 \times 10^{12}$ watts, (2) geothermal heat, heat conducted and convected from the earth's interior, amounting to about $32 \times 10^{12}$ watts, and (3) tidal energy from the combined potential and kmetic energy of the earth-moon-sun system of about $3 \times 10^{12}$ watts. Energy input from solar radiation is approximately 5000 times that from the other two sources combined. It is by a wide margin the largest source of energy avalable to the earth and also has an expectancy of future continuation for a time comparable to that of the past duration of the solar system.

The energy from each of these sources, after undergoing a sequence of degradations, eventually leaves the earth by radiation into outer space. In the case of solar energy about $35 \%$, the earth's "albedo," 1s directly reflected. The remaining $65 \%$, after undergoing various degradations, eventually terminates as heat at the lowest local surface temperature and is then reradiated into outer space as long-wavelength, low-temperature radiation. Of the total influx of solar radiation, about $43 \%$ is absorbed by the earth's atmosphere and surface materials and converted directly into heat. About $22 \%$ is expended in the evaporation, circulation, and precipitation of water in the hydrologic cycle; a small fraction of $1 \%$ is expended in winds, ocean currents, and waves of atmospheric and oceanic circulations and interactions. Finally, a still smaller fraction, about $40 \times 10^{12}$ watts, 1 captured by the chlorophyll of plant leaves in the process of photosynthesis whereby the inorganic materials, $\mathrm{CO}_{2}$ 
and $\mathrm{H}_{2} \mathrm{O}$, are converted into organic carbohydrates with an accompanying chemical storage of energy This becomes the source of the biological energy requirements of the entire plant and animal kingdoms

Photosynthetically stored energy is released by the reverse reaction of oxidation whereby

$$
\text { Oxygen + organic materials } \rightarrow \mathrm{H}_{2} \mathrm{O}+\mathrm{CO}_{2}+\text { heat }
$$

On the average, the rate of decay and oxidation of plant and anmal materials is approximately equal to the rate of photosynthesis However, during geologic time, at least since the Cambrian, a minute fraction of this material was deposited in peat bogs or other oxygen deficient environments of incomplete decay Eventually this material was buried by great thicknesses of sedimentary sands and muds, and through subsequent transformation has become the earth's supply of the fossil fuels The present accumulation of fuels therefore represents chemical storage of a small part of the solar energy incident upon the earth durng the last 600 million years

Geothermal energy occurs principally as heat, although a fraction is responsible for the mechanical activities of volcanoes and hot springs Tidal energy is responsible for the oscillation of seawdter, which produces the semidiurnal cycle of the rise and fall of the tides and associated tidal currents This energy is then dissipated by friction into low temperature heat

At an early stage our ancestors must have existed in some kind of ecological equilibrum with the other members of the plant and animal kingdoms and competed with these members for a share of the contemporary solar energy essential for their existence At that stage man's sole capacity for energy utilization, in common with the other members of the animal kingdom, must have been limited to the food required - then as now probably about an average of 2000 kilocalories or about 100 watts per capita per day

Since that early stage the human species has distınguished itself from all other members of the animal kingdom in its inventiveness of means for capturing an ever larger fraction of the contemporary flux of energy Initially, this inventiveness consisted principally in the manipulation of the contemporary ecological system The use of tools and weapons, the control of fire, the invention of clothing and housing, and eventually the domestication of plants and anımals and the employment of beasts of burden all increased the supply of energy avalable to man and continuously upset the ecological equilibrium in favor of an increase in numbers and a geographical spread of the human species, with corresponding adjustments of all other plant and animal populations

Eventually the conquest of energy was extended to nonbiological sources when the Egyptians used the power of wind to propel saling shıps on the Nile and the Romans used wdter power for grinding grain About 5000 years dgo the energy of wood was extended to the nonbiological use of smelting metallic ores

Although the prehistoric details are only dimly known, from the million or so years of time involved, the rates at which these successive changes occurred must have 
been extremely slow. However, since the time sedentary agriculture was introduced, estimated to have been 8000 to 10,000 years ago, the pace of successive developments has progressively quickened. Even so, the rate of increase of energy utilization must have been so slow that the increase of population was able to keep pace. Hence, the rate of energy consumption per capita could not have been more than a few times more than the biological requirements for food alone.

Escape from dependence upon the contemporary flux of energy with its approximately fixed energy allotment per capita was not possible until a larger and more concentrated source of energy became avalable. This occurred about nine centuries ago when the inhabitants of the northeast codst of England, near Newcastle-on-Tyne, discovered that the black rocks along the seashore-hence known as "sea coals" - would burn. The mining of coal as a continuous enterprise soon spread to all the coal fields of Great Britain and Western Europe. Next, in 1857 in Romania and in 1859 in the United States, the exploitation of the second major source of energy from fossil fuels, petroleum, began.

Since about the year 1700 , an associated technology has evolved along with the exploitation of energy from the fossil fuels. This included the development of the steam engine and its use for stationary, and, later, mobile mechanical power and the use of coal for the smelting of metals, principally 1ron. With the discovery of petroleum came the internal combustion engine followed by the motor vehicle and the arrplane. The development of means for the transmission of electric power, during the latter part of the nineteenth century, has made possible individual power units, including water-driven generators, of more than 1000 megawatts (Mw) capacity as compared with units of only a few hundred kilowatts based on mechanical transmission of power.

The mining of coal as a continuous enterprise began about the twelfth century and has steadily increased ever since. Although scattered statistics on production during the earlier centuries exist, statistics on the annual production of coal and lignite prior to the year 1860 are difficult to assemble. We do know, however, that by 1860 the annual production rate had reached $138 \times 10^{6}$ metric tons and by $1965,280 \times 10^{9}$ tons (F1g. 3). The rate of production of coal and lignite during the years before 1800 must have been almost insignificant as compared with that which followed 1800 . From avalable data it can be estmated that the average rate of growth in the production rate before 1860 must have been about $2 \%$ per year. The cumulative production during the preceding elght centuries has been estımated to be about $7 \times 10^{9}$ metric tons. By 1965 this had reached $125 \times 10^{9}$, and by 1970 it was approximately $140 \times 10^{9}$ metric tons. Hence, coal production during the 110 -year period from 1860 to 1970 was about 20 times that of all preceding history. Similarly, the amount of coal produced during the 30-year period 1940 to 1970 was equal to that of all preceding history.

The rate of growth of production since 1860 falls into three distinct episodes [Fig. 3(a)] (1) a steady exponential growth until about the beginning of World War I, (2) a slowdown between World Wars I and II, and (3) a resumption of rapid growth 


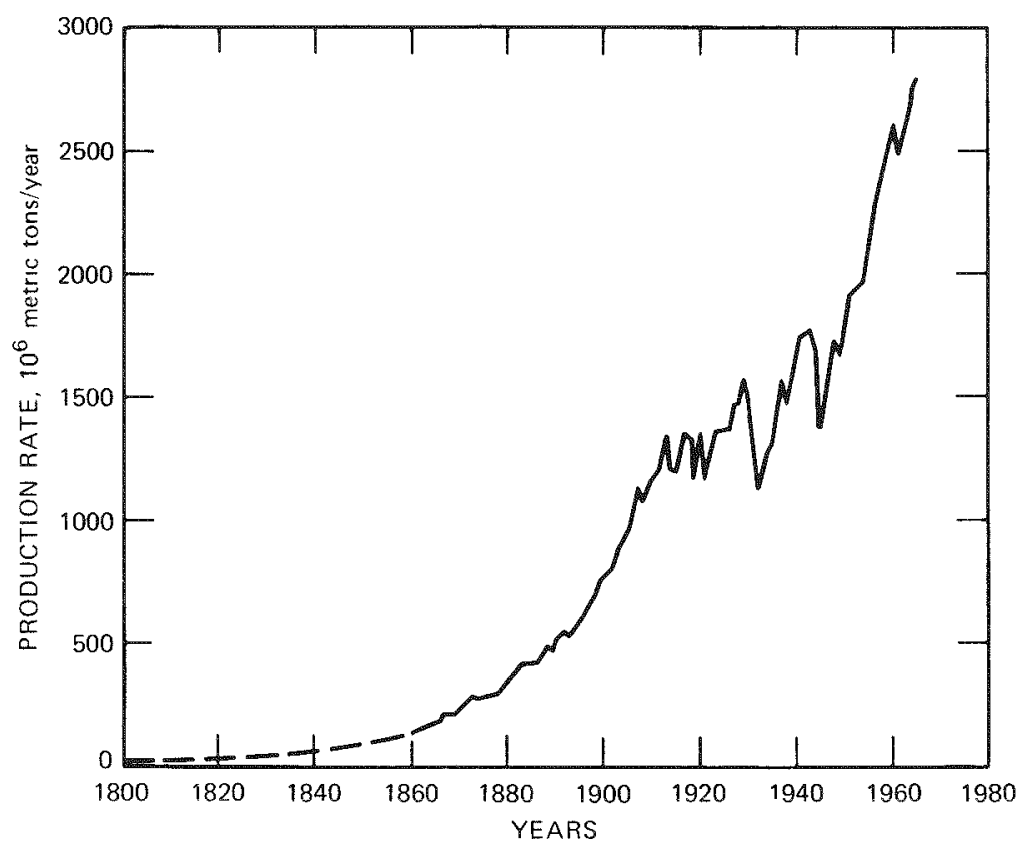

(a)

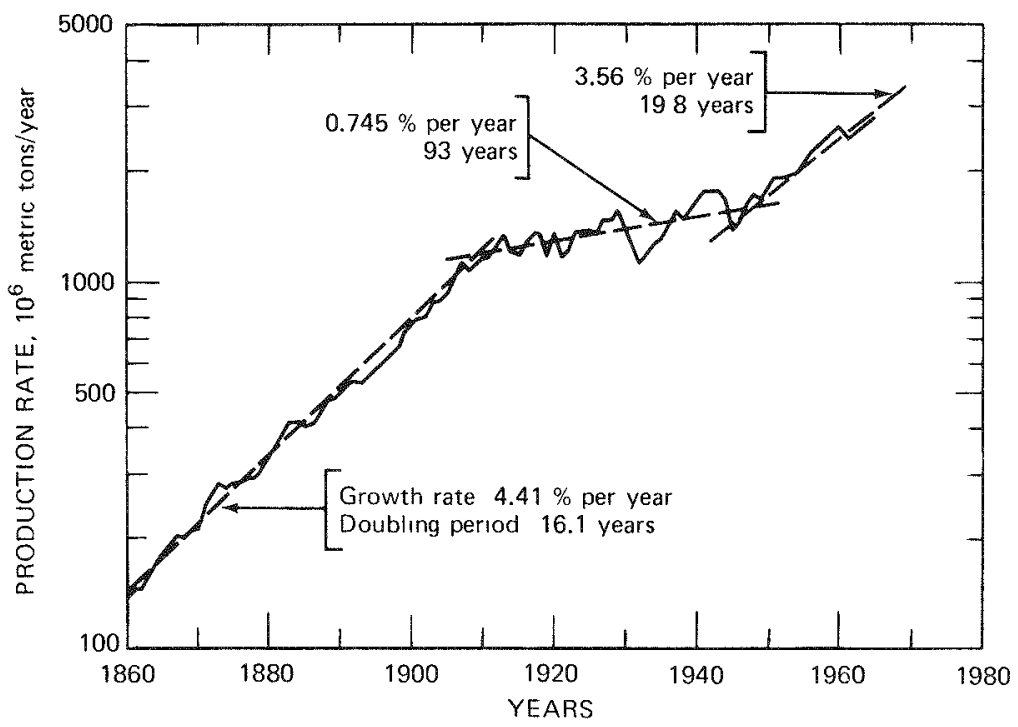

(b)

Fig. 3 World production of coal and lgnite. (a) Arithmetic scale. ${ }^{2}$ Dashed portion is an approximation. (b) Semilogarithmic scale. ${ }^{3}$ 
following World War II. This is shown even more clearly in Fig. 3(b), where a straight-line segment indicates an exponential growth at a constant rate of increase per year or a rate of production that doubles at equal successive intervals of time. Hence, Fig. 3(b) shows that during the period 1860 to 1914 annual production increased at a steady rate of $4.41 \%$ per year with a doubling period of 16.1 years. During the second period, 1914 to 1946 , the growth rate reduced to only $0.745 \%$ per year with a doubling period of 93 years. Finally, during the period since 1946, a growth rate of $3.56 \%$ per year with a doubling period of 19.8 years has been achieved.

The annual production of crude oil (Fig. 4) had reached about $11.2 \times 10^{9}$ barrels per year by 1965 , and by the end of 1970 , about $16.2 \times 10^{9}$. Cumulative production amounted to $233 \times 10^{9}$ barrels. Of this, the 103 -year period from 1857 to 1960 was required to produce the first half, and the second half required only the 10-year period from 1960 to 1970. Figure 4(b) shows that, except for a slight rise during the 1920s and a slight downward offset during World War II, the curve follows a straight-line exponential growth rate from 1880 , corresponding to an annual rate of increase of $6.94 \%$ with a doubling period of 10.0 years.

Since coal is measured in metric tons and oil in U.S. barrels, the two cannot be compared directly. When the thermal energy content of the separate fuels is expressed in a common unit of energy, however, they can be compared. In Fig. 5 this has been done in terms of the energy content expressed in units of kilowatt-hours of heat. The figure shows that the energy from crude oil was barely significant by 1900 but that by 1965 it was approximately equal to that from coal and lignite. By 1970 crude oil accounts for about $57 \%$ of the total energy from coal and crude oil combined. When we include the additional energy from natural gas and natural-gas liquids, we find that by 1970 about two-thirds of the energy from fossil fuels is contributed by petroleum fluids, only about one-third by coal. From 1850 to 1907 coal production in the United States (Fig. 6) increased exponentially, with a growth rate of $6.58 \%$ per year and a doubling period of 10.5 years. After 1907 the growth rate broke away sharply from its earlier trend, and during the last half century production has fluctuated about a mean rate of approximately $500 \times 10^{6}$ short tons per year.

Production of crude oil in the United States (Fig. 7) began in 1859 and from 1874 to 1929 it increased exponentially with a rate of increase of annual production of $8.27 \%$ and a doubling period of 8.4 years. Since 1929 , following a minor setback during the depression of the $1930 \mathrm{~s}$, the growth rate has progressively diminished, and in 1970 it was approximately zero.

Until after 1940 a great deal of the natural gas produced in the United States in association with oil was "flared" by burning at the wellhead because of inadequate pipelines and market facilities. Statistics until recently have accordingly been restricted only to that fraction of the gas produced that was delivered to the consumer. Since World War II, in consequence of the construction of "big-inch" pipelines for delivery of gas to the major residential and industrial centers, such waste of gas has been curtailed and marketed statistics reflect approximately the total net production (Fig. 8). From about 1903 to 1965 annual production of marketed gas increased exponentially, with an annual growth rate of $6.57 \%$ and a doubling period of 10.5 


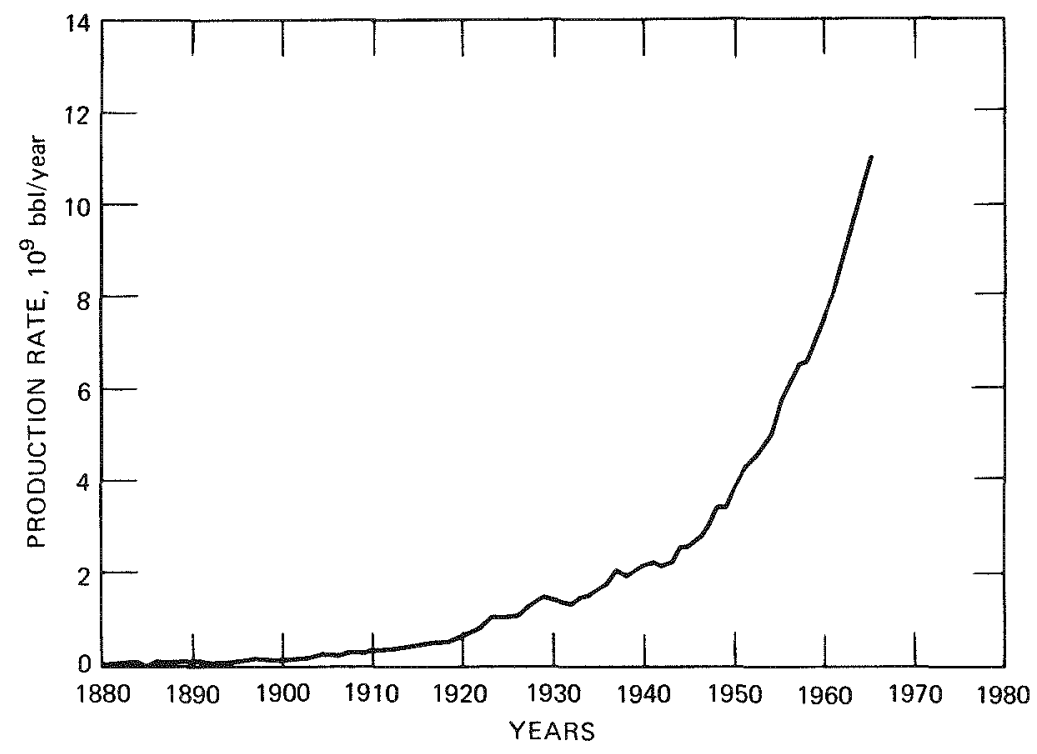

(a)

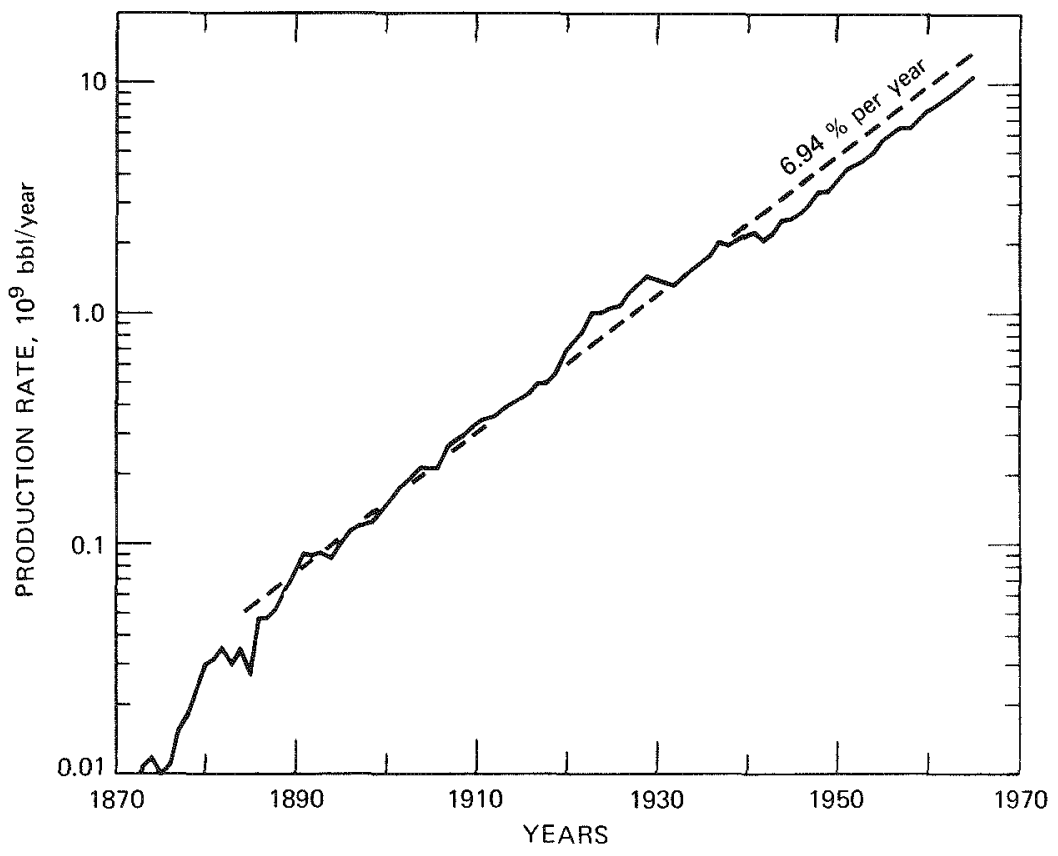

(b)

Fig. 4 World production of crude oil. (a) Arithmetic scale. ${ }^{2}$ (b) Semilogarithmic scale. ${ }^{3}$ 


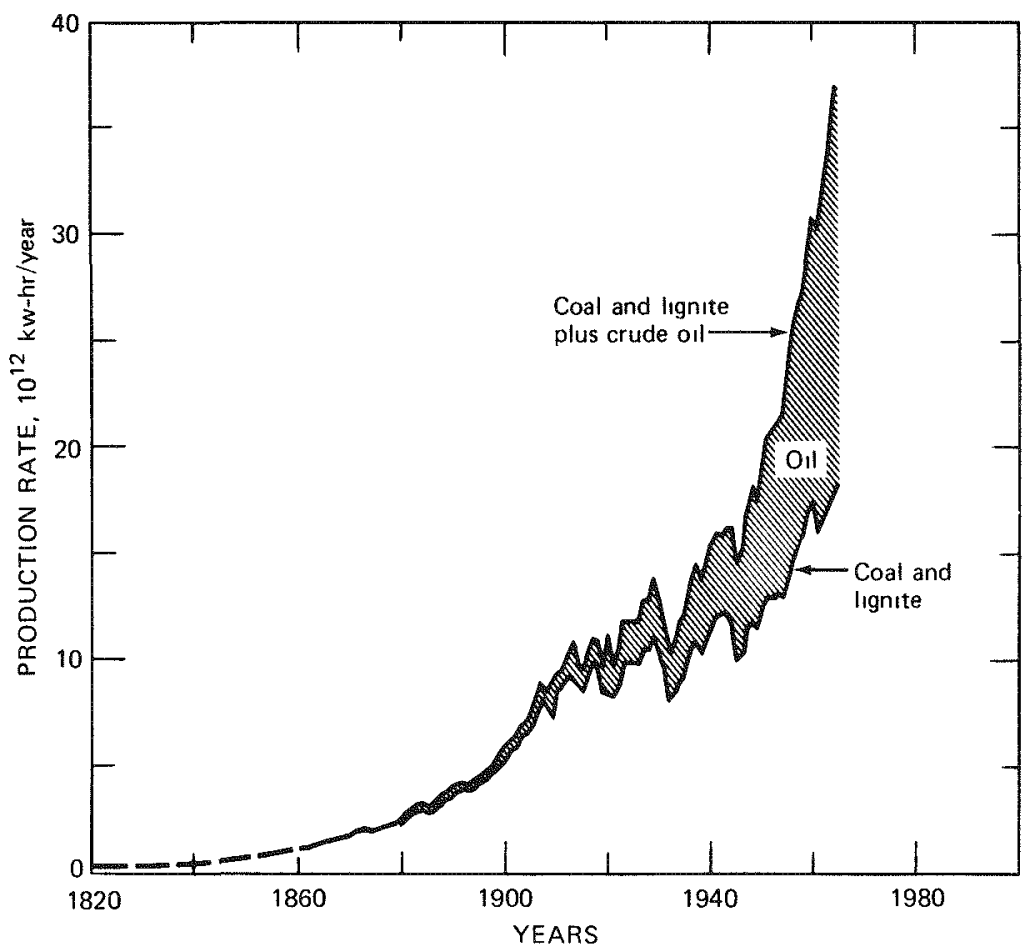

Fig. 5 World production of thermal energy from coal and lignite plus crude oil. ${ }^{2}$ Lower curve, energy content of coal and lignite. Shaded area, additional energy contributed by crude o1l. Upper curve, total energy of coal, lignite, and crude oll.

years. By 1970 the rate of production had reached $22 \times 10^{12} \mathrm{cu} f t$ per year (at $60^{\circ} \mathrm{F}$ and a pressure of $14.73 \mathrm{lb} / \mathrm{sq} \mathrm{in}$.).

The growth in the rate of production of total industrial energy in the United States from codl, oll, natural gas, water power, and nuclear power is shown in Fig. 9. Agdin, we note that from 1850 to 1910 the production rate increased at a steady exponential rate of $6.91 \%$ per year with a doubling period of 10.0 years. At this point the curve broke sharply downward It then continued at the greatly reduced average rate of $177 \%$ with a doubling period of 39 years until about 1958. Subsequently it increased at a higher rate of $4.6 \%$ per year with a doubling period of 15 years.

The rate of energy consumption since World War II has been somewhat higher than the rate of production because about 1946 the United States became a net importer of petroleum. Imports have steadily increased; by 1970 imports amounted to about one-thi1d of domestic petroleum production or one-fourth of domestic consumption. 


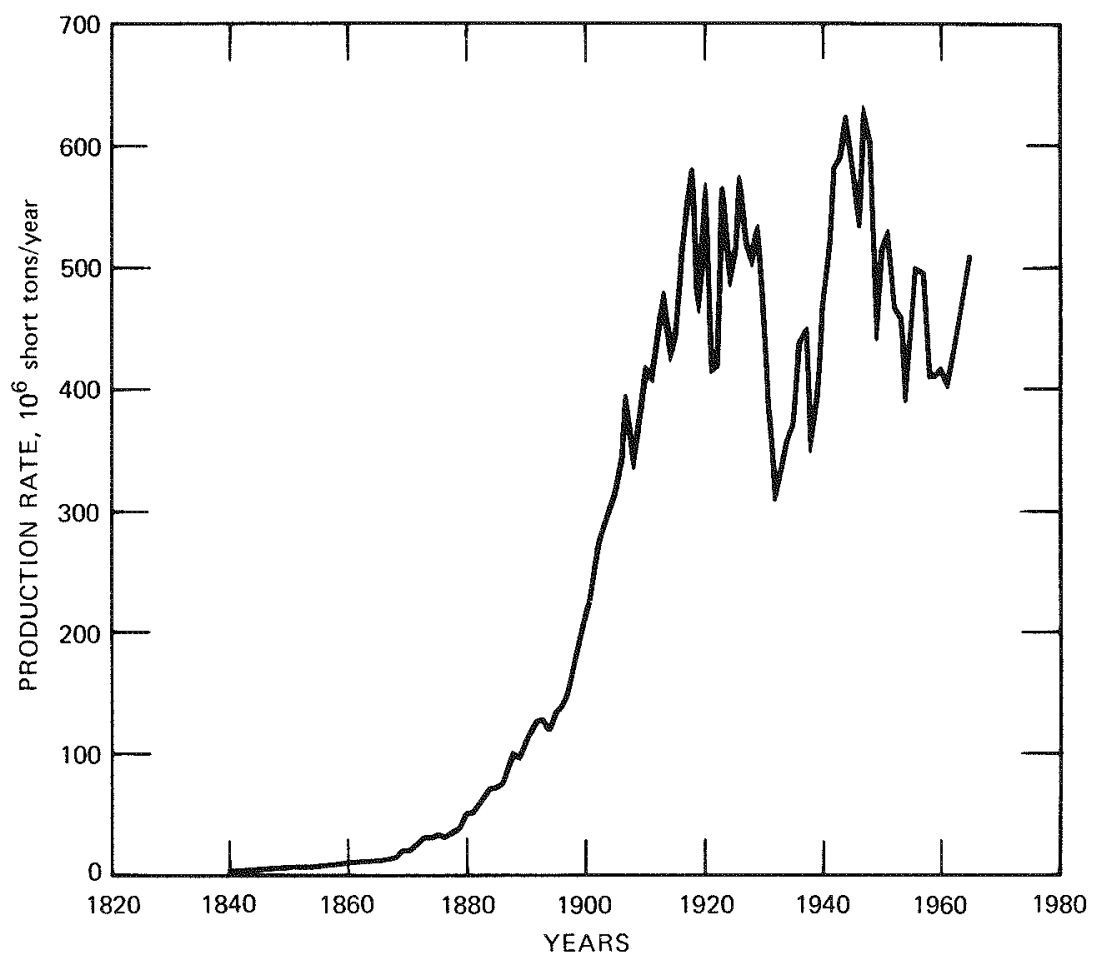

(a)

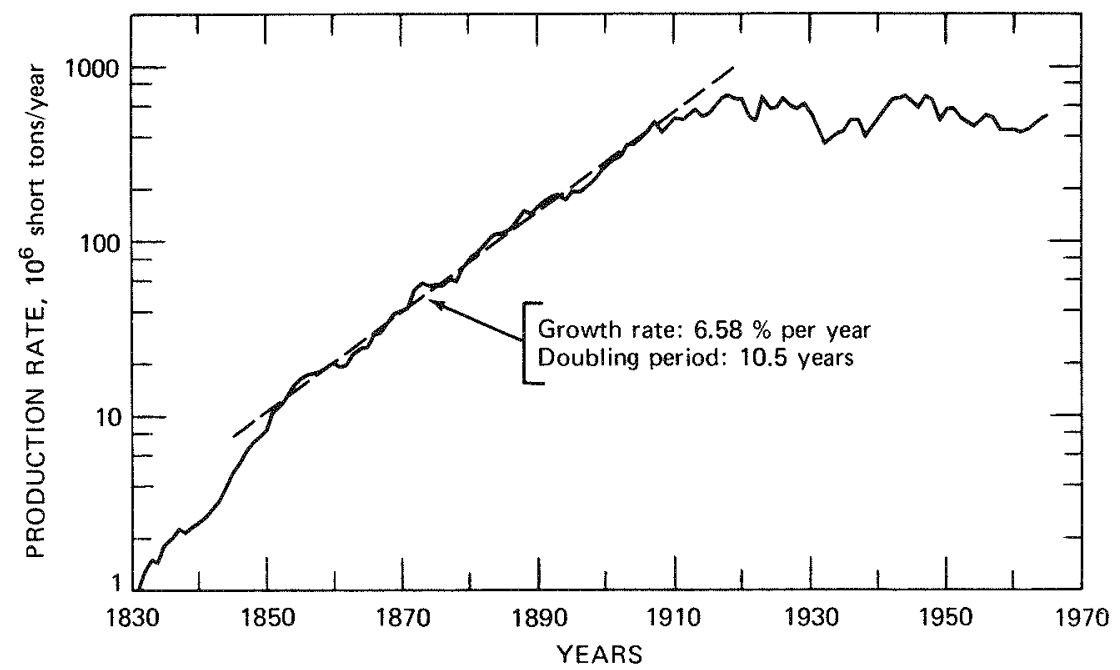

(b)

Fig. 6 U. S. production of coal and lignite. (a) Arithmetic scale. ${ }^{2}$ (b) Semilogarithmic scale. 


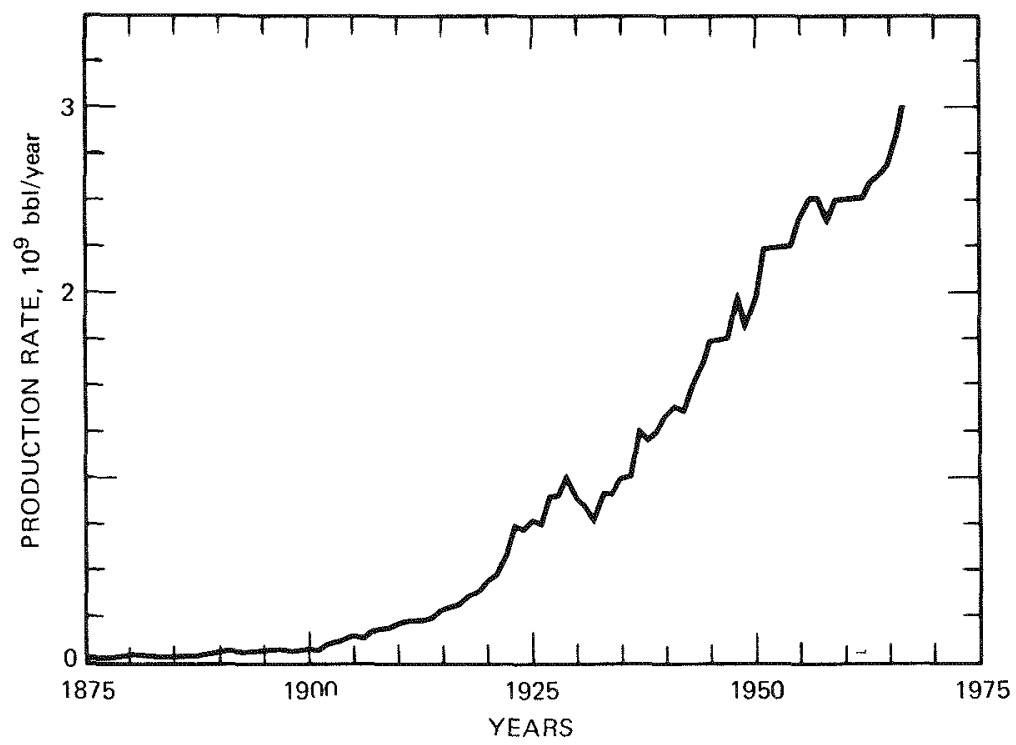

(a)

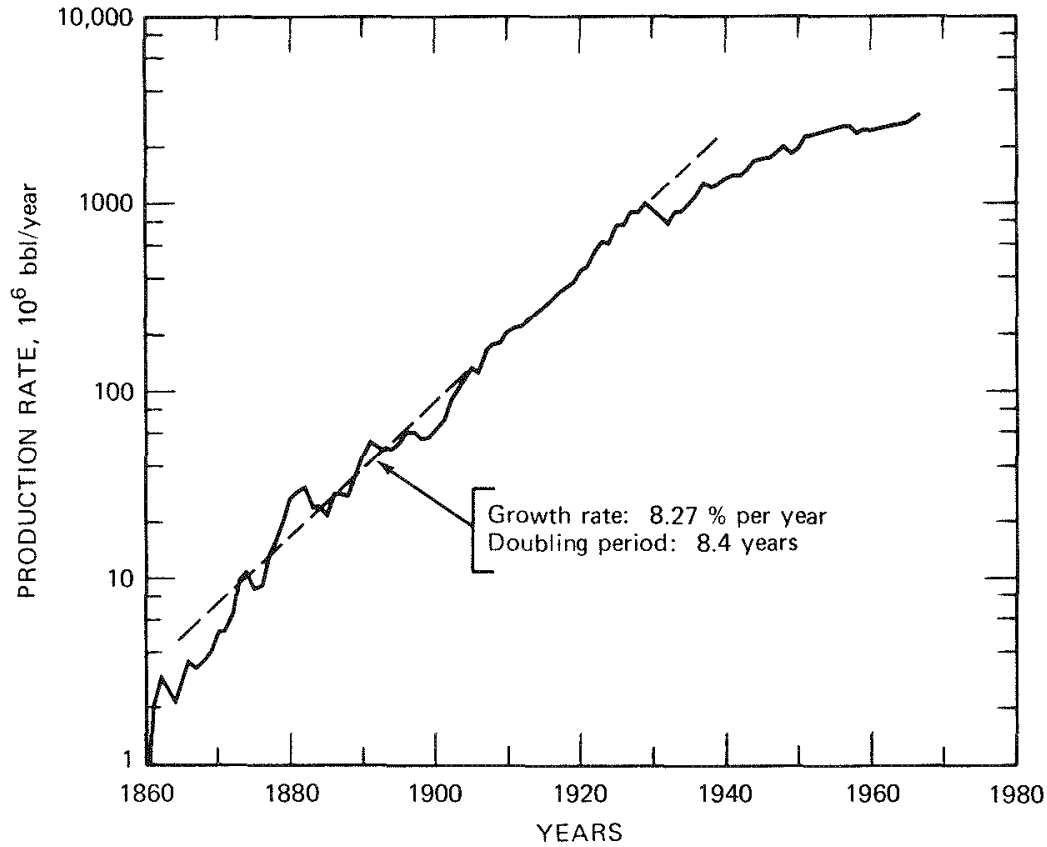

(b)

Fig. 7 U. S. production of crude oil, exclusive of Alaska. (a) Arithmetic scale. ${ }^{2}$ (b) Semilogarithmic scale. 


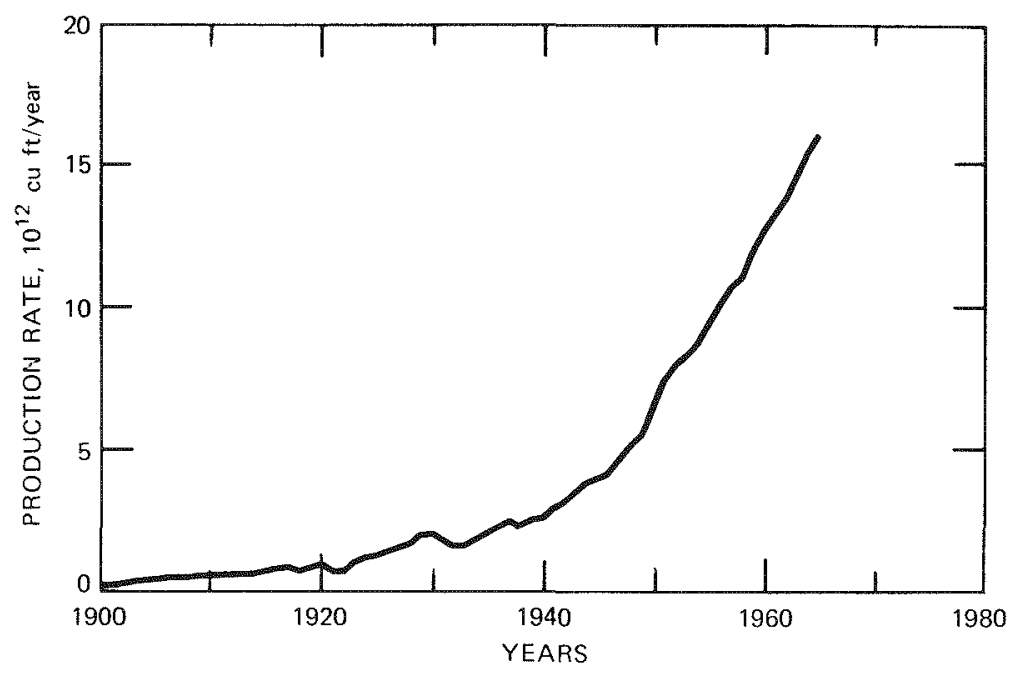

(a)

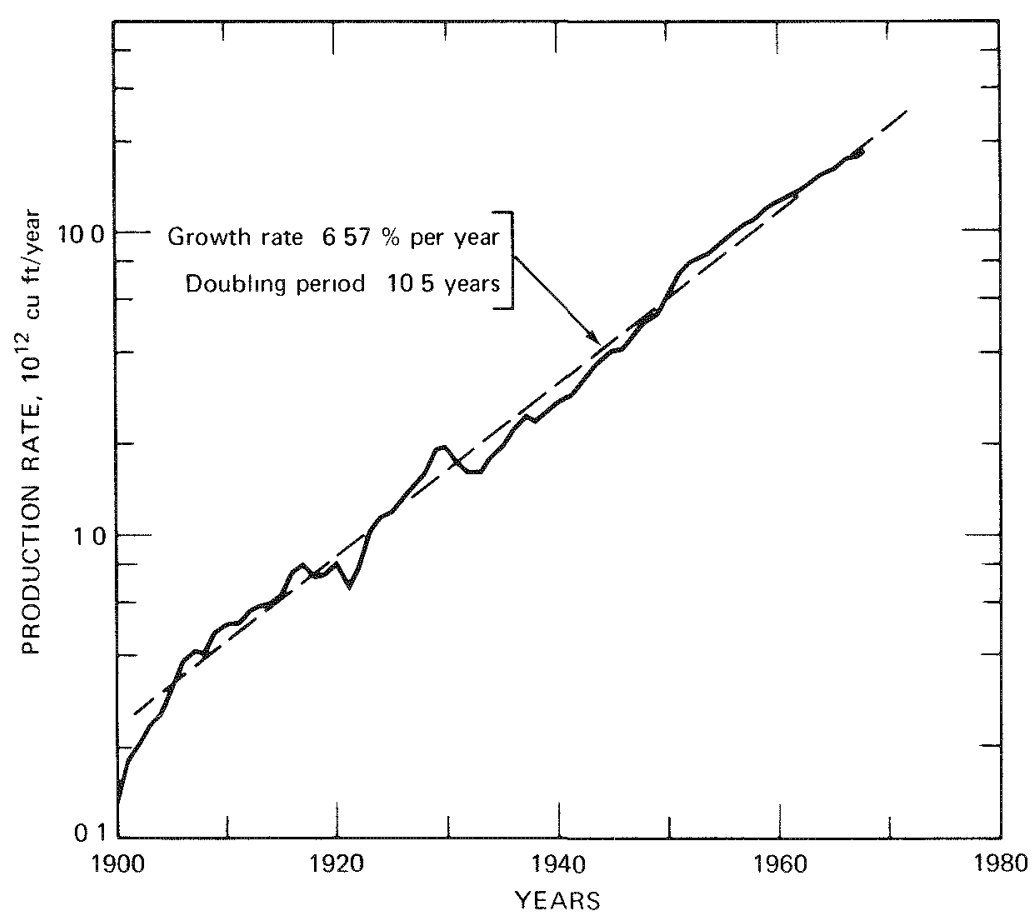

(b)

Fig. 8 U, S. production of marketed natural gas, exclusive of Alaska. (a) Arithmetic scale. ${ }^{2}$ (b) Semilogarithmic scale. 


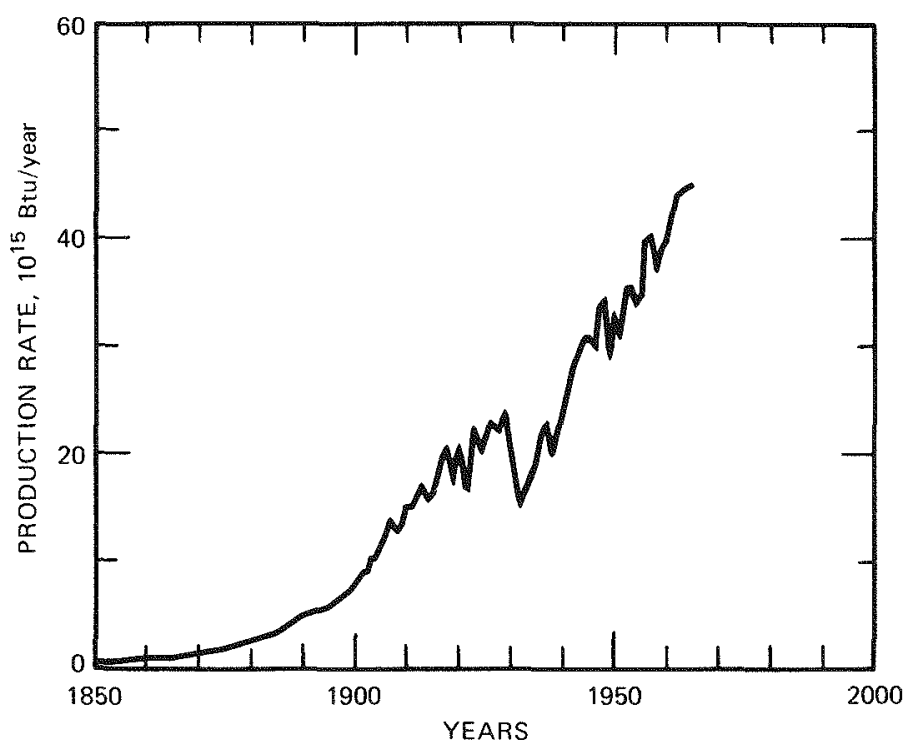

(a)

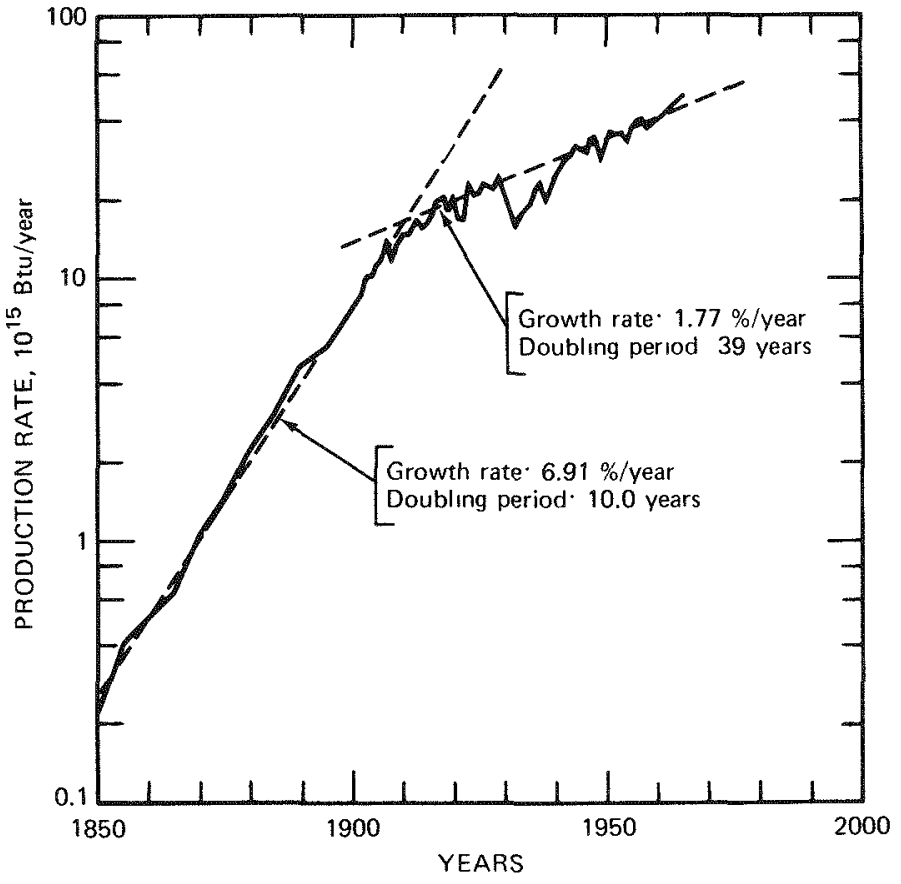

(b)

Fig. 9 U. S. production of energy from coal, oil, gas, water, and nuclear power. (a) Arithmetic scale. (b) Semilogarithmic scale. 


\section{FUTURE OF PRODUCTION OF ENERGY FROM FOSSIL FUELS}

From this brief review of the growth of energy production from fossil fuels, we have seen that in each instance production has increased initially at an almost constant exponential rate between the limits of about 4 and $8 \%$ per year with doubling periods of between about 8 and 16 years Also, in each instance, this steady exponential growth has been sustained for the order of a century, then, with the exception of world production of crude oll, the growth rate has begun to slow down. A question of great interest regarding the future of these curves is "How much longer can the growth rates that have prevalled during the last century be continued?"

An approximate answer to this question can be obtained when we consider the nature of the fossil fuels. These fuels are derved from the remans of plants and anımals which were bured under conditions of incomplete decay over a geologic time span of some 600 million years. Although burial and preservation are still occurring, their present rates are so slow that no significant additions to the world's supply of fossil fuels are likely to accrue within a period of less than a millon years. Hence, in the exploitation of fossil fuels, it is evident that we are simply depleting a fixed and finite initial supply with no replacement within the time span of the next few centuries

The manner of exploitation of a fossil fuel for its energy content is shown diagrammatically in Fig. 10. The fuel is extracted from its underground deposit either by mining or by drilling. The energy of the fuel is then extracted chemically in the form of heat by a combustion reaction of the form

$$
\text { Fuel }+\mathrm{O}_{2} \rightarrow \mathrm{H}_{2} \mathrm{O}+\mathrm{CO}_{2}+\text { heat }
$$

Especially in the case of coal, mineral impunties are also present which produce the gas $\mathrm{SO}_{2}$ and ash. The material constituents are thus returned to the atmosphere or to the earth. The energy content, however, after various transformations, whether directly as heat or from thermal to mechanicd to electrical energy, eventually is reduced to heat at the lowest local temperature and is then radiated into outer space. Hence, the material constituents of the fossil fuels remain on the earth but the energy content, after being irreversibly degraded, leaves the earth. The fossil fuels, therefore, are absolutely exhaustible.

A guiding principle of fundamental importance in estimating the future course of the production rate of any given exhaustible resource is a consequence of a geometrical property of the curve of the rate of production when plotted arithmetically as a function of time. Consider a vertical column extending from the time-axis to the curve of the rate of production. Let the base of this column be a small interval of time dt and its height be the production rate

$$
P=\frac{d Q}{d t}
$$




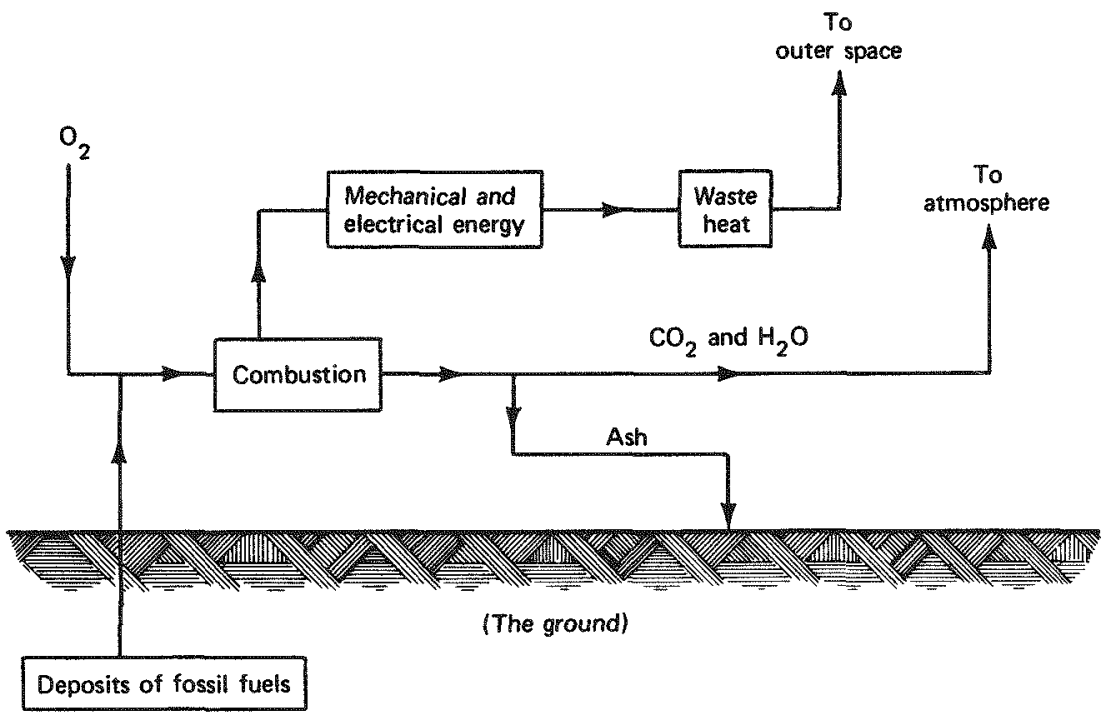

Fig. 10 Flow diagram for the production and combustion of fossil fuels.

where $\mathrm{dQ}$ is the quantity of the substance produced during the time interval $\mathrm{dt}$. Then the area of this column, which will be the product of its base times its altitude, will be the quantity $d Q$ produced during $d t$,

$$
\frac{\mathrm{dQ}}{\mathrm{dt}} \times \mathrm{dt}=\mathrm{dQ}
$$

The total area under the curve from the beginning up to any given time must represent the cumulative production Q up to that time.

Now consider how the curve of production rate must behave during a complete cycle from the beginning of the production of the resource until its exhaustion. The rate-of-production curve must begin at zero and then, after a period of steady increase, pass one or more maxima and eventually decline to zero as the resource becomes exhausted. The total area under this curve then represents the ultimate cumulative production $Q_{\infty}$, and the basic equation of the process must be be

$$
\mathrm{Q}_{\infty} \overline{\overline{<}} \mathrm{Q}_{\mathrm{i}}
$$

where $Q_{i}$ is the quantity of the resource initially present. This principle is illustrated in Fig. 11, which shows the complete production cycle of an exhaustible resource. If now, by geological or other means, we can estimate how much of the given resource was originally present, we can then extrapolate the production curve as known up to the present into the future, subject to the condition that when it returns to zero the area under the curve must not exceed the estimate of the initial quantity. 


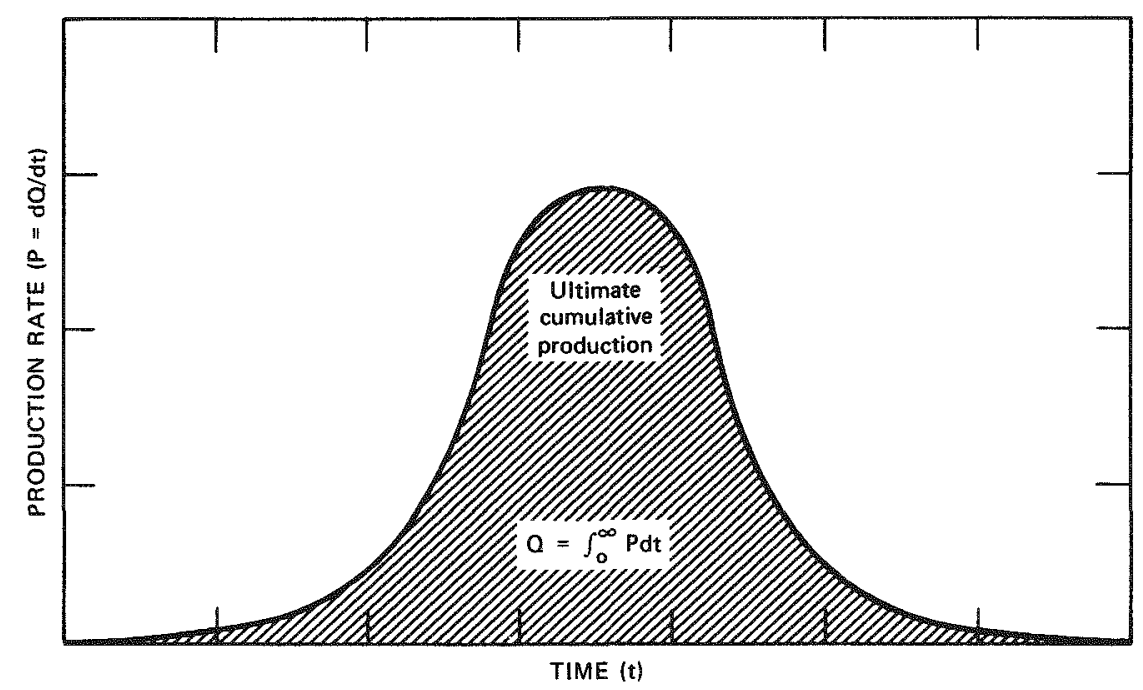

Fig. 11 Complete cycle of an exhaustible resource. Area under curve is proportional to cumulative production. [From M. King Hubbert, Nuclear Energy and the Fossil Fuels, in Drilling and Production Practice (1956), p. 12, American Petroleum Institute, New York.]

\section{Application to Coal}

Coal, because it occurs in stratified beds or seams which commonly extend over wide areas and also frequently crop out on the surface, is a comparatively easy resource to estimate. Most of the areas in the world which are underlain by coal beds are known. Inventories of world coal resources have been compiled successively since 1913. The most recent is that for the year 1967 made by Averitt ${ }^{4}$ of the U.S. Geological Survey. This compilation comprises an estimate of all the minable coal originally present to depths of $4000 \mathrm{ft}(1.2 \mathrm{~km})$ and in beds $14 \mathrm{in} .(36 \mathrm{~cm})$ or more in thickness. In mining, roughly half the coal is left in the ground. Hence "minable coal" is taken to be $50 \%$ of that estimated to be present. According to Averitt's estimates the total original quantity of minable coal in the world amounted to an estimated 7640 billion metric tons. Of this, 5000 billion metric tons was in Asia; 2100 in North America; 377 in Europe; and 182, or only 3.2\%, divided between the three continental areas of Africa, South and Central America, and Oceania (including Australia). By countries, 4310 billion metric tons, or $56 \%$ of the world's original coal supply, was in the USSR, and 1486, or $19 \%$, in the United States.

The quantity of coal consumed by 1970 amounted to 140 billion metric tons, or to about $2 \%$ of the quantity initially present. Using the principle illustrated in Fig. 11 and combining the curve of coal production with estimates of the world's minable coal, we can construct curves of the complete cycle of world coal production. 


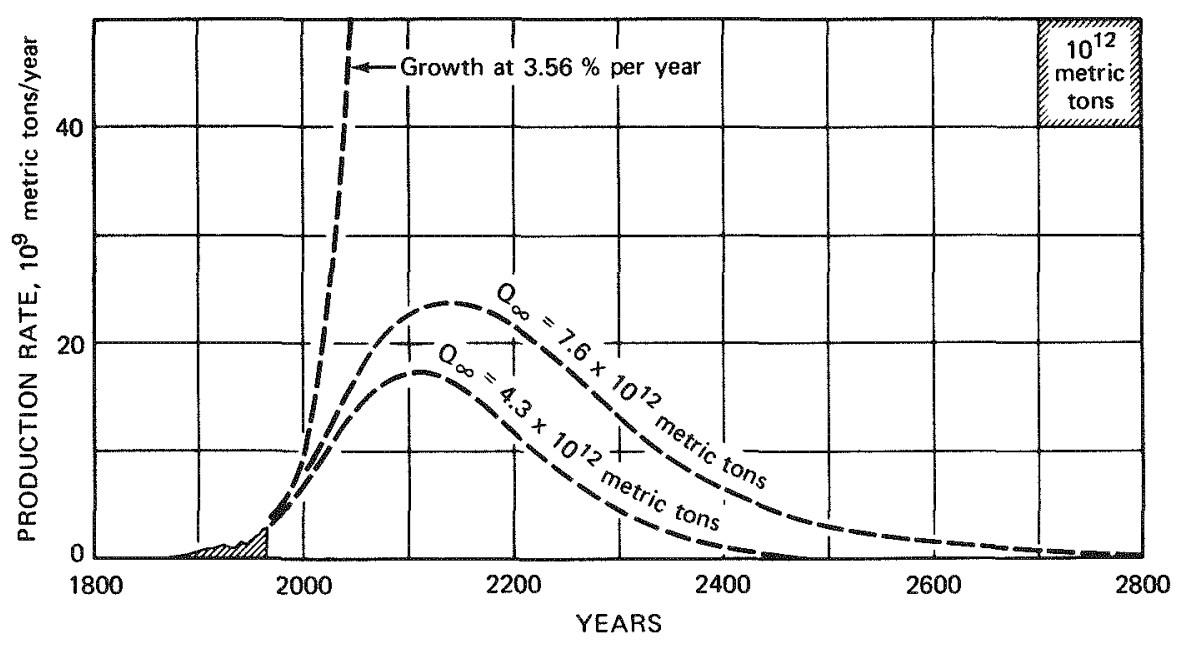

Fig. 12 Complete cycle of world coal production for two values of $Q_{\infty}$ (Ref. 2 ).

Figure 12 shows two such curves plotted using two different values for $Q_{\infty}$ (the estimated ultimate amount of coal to be produced), Averitt's value of $7.6 \times 10^{12}$ metric tons and a smaller value of $4.3 \times 10^{12}$. In view of the depth and thinness of some of the seams in the Averitt estimate, the smaller figure may be the more realistic of the two.

In Fig. 12 the area scale is shown by the grid square in the upper right-hand corner, which has a vertical dimension of $10 \times 10^{9}$ metric tons/year and a horizontal dimension of 100 , or $10^{2}$, years. Hence its area represents

\section{$\left(10 \times 10^{9}\right.$ metric tons $/$ year $) \times(100$ years $)=10^{12}$ metric tons}

Therefore, for $\mathrm{Q}_{\infty}=7.6 \times 10^{12}$ metric tons; the area under the curve during a complete cycle of production cannot exceed that of 7.6 grid squares. For the smaller value of $Q_{\infty}$, the area cannot exceed that of 4.3 grid squares.

If we assume a modest future growth in the rate of coal production of not more than three more doublings, then we obtain the two curves shown in Fig. 12 for the complete cycle of production. If higher peak rates of production should be achieved, the two curves would be higher and narrower than those shown, but the respective areas would not be changed. Should lower peak rates prevail, the time span of the curves would be increased.

The dashed curve shown extending to the top of Fig. 12 represents what the production rate would be if the growth rate of $3.56 \%$ per year that has prevailed since World War II continues for another 75 years. According to the more probable curve shown in Fig. 12, it appears that the peak in world coal production will probably occur sometime near the period 2100 to 2150 . Then, if we disregard the long periods 


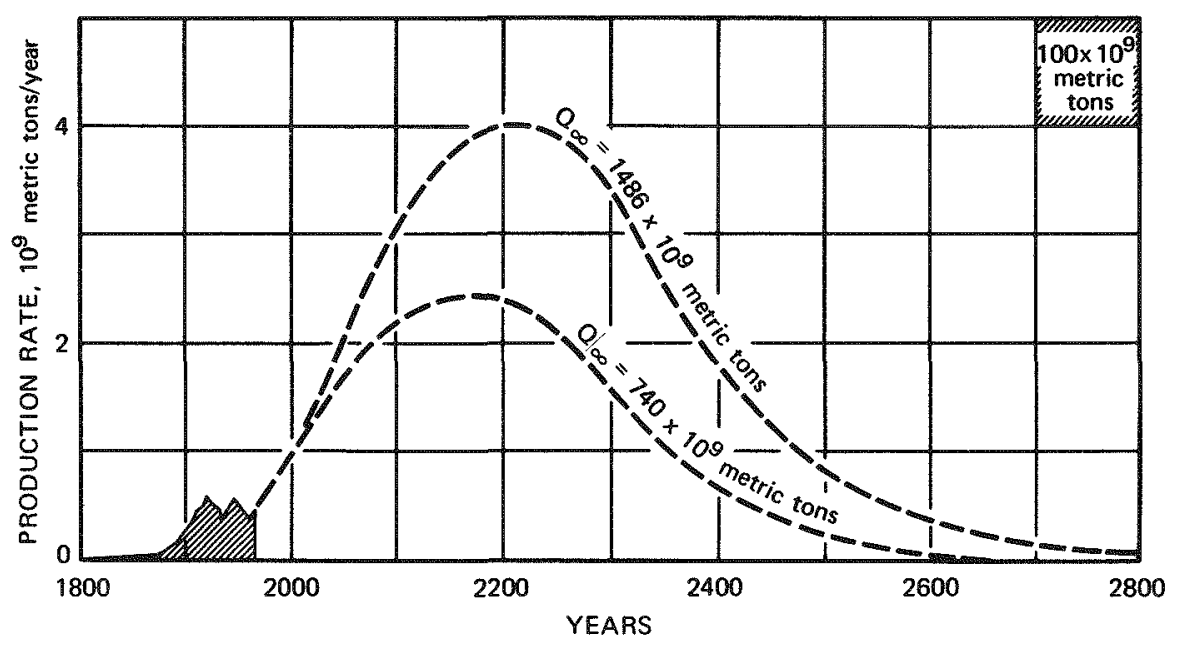

Fig. 13 Complete cycle of U. S. coal production for two values of $Q_{\infty}$ (Ref. 2).

of time required to produce the first and last $10 \%$ of the ultimate cumulative production, $\mathrm{Q}_{\infty}$, it appears that the middle $80 \%$ will probably be consumed during the three centuries between the years 2000 and 2300 .

The corresponding complete cycles of coal production in the United States are shown in Fig. 13. Here also two different values are used for $Q_{\infty}$, that of Averitt of $1486 \times 10^{9}$ metric tons and a smaller value of approximately half this amount. For the peak rates assumed, the peak in production should occur about the year 2200 , and the consumption of the middle $80 \%$ should require the three or four centuries centered at about the year 2200 .

\section{Petroleum}

Petroleum, consisting principally of crude oil, natural gas, and natural-gas liquids, because of its fluid nature differs markedly from coal in its manner of occurrence underground. Whereas coal occurs in strata of large areal extent, oil and gas accumulations are found in the pore spaces of sedimentary rocks in volumes of restricted areal and vertical extent. The pore spaces of sedimentary rocks are normally filled with water. In this porous-rock and water environment, oil and gas are driven into traps that are usually in domal structural configurations of porous rocks overlain by less pervious strata. In size, oil and gas fields range from a few hundred meters to more than $100 \mathrm{~km}$ in horizontal dimensions, and from a meter or so to hundreds of meters vertically. By far the greatest number of such fields are less than a square kilometer in area. 
For these reasons, the estimate of the ultimate amount of oil or gas that a given region will produce is much more difficult than corresponding estimates for coal. However, as geological and geophysical mapping in a developing region progresses and as drilling and production proceed, this cumulative knowledge permits successively more accurate estimates of how much oil or gas the region may ultimately produce.

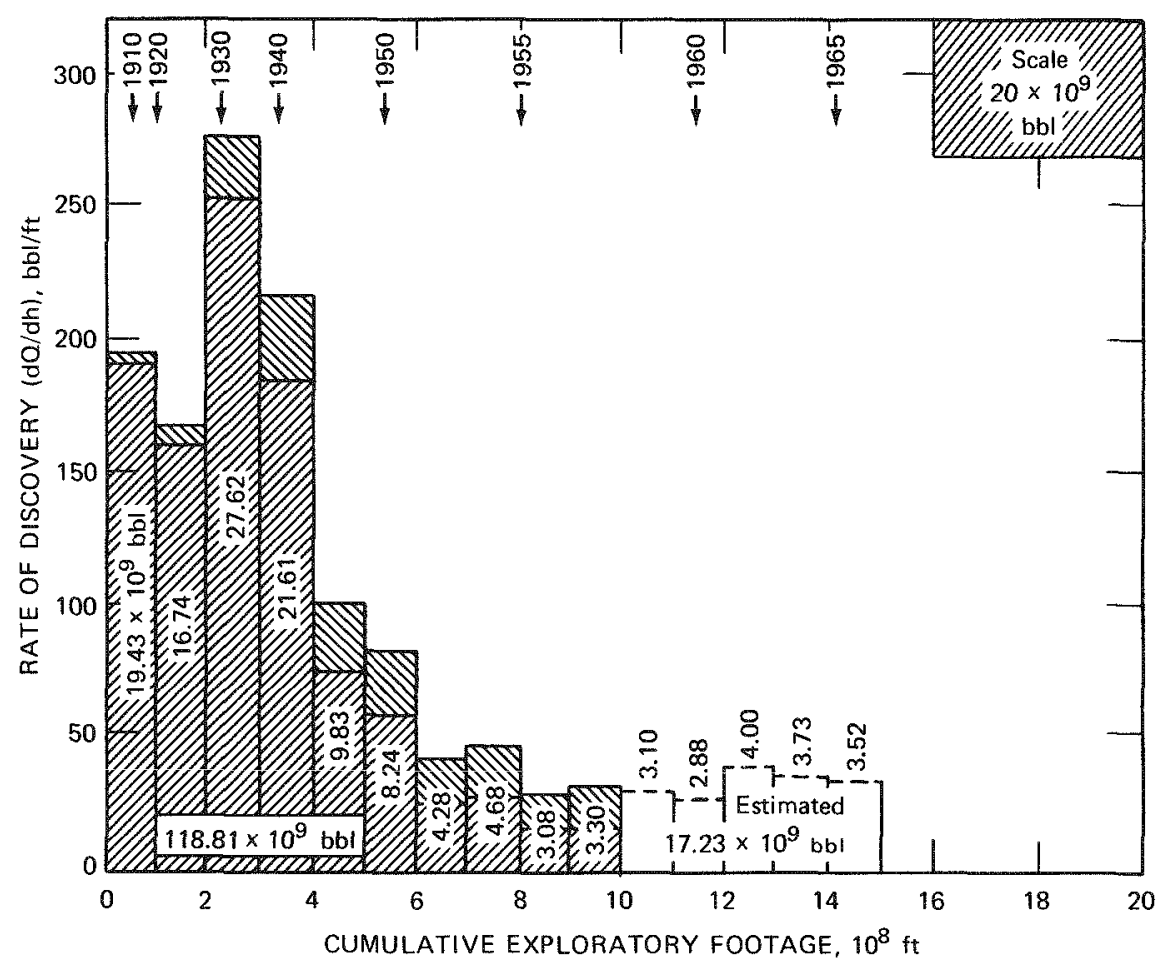

Fig. 14 U. S. discoveries of crude oil per foot of exploratory drilling (Alaska excluded), averaged for each $10^{8} \mathrm{ft}$ vs. cumulative exploratory drilling. [From M. King Hubbert, Degree of Advancement of Petroleum Exploration in the United States, Amer. Ass. Petrol. Geol. Bull., 51: 2223 (1967).]

In the United States, which is one of the two earliest oil-producing countries of the world, the state of development is the most advanced. Therefore, the geological and statistical information accumulated within the last 20 years makes possible a number of different methods that give reasonably consistent estimates of the ultimate amounts of oil and gas that may be produced in the United States.

One of these methods is shown in Fig. 14. This figure shows the amount of oil discovered in the United States for each successive 100 million feet of exploratory drilling and the barrels of oil discovered per foot as a function of cumulative feet of uxploratory drilling from 1860 to 1965 . By 1965 cumulative exploratory drilling 
amounted to $15 \times 10^{9} \mathrm{ft}$, or to 15 units of $10^{8} \mathrm{ft}$ each. The first of these drilling units required the 60-year period from 1860 to 1920 , the last half-dozen have averaged about 2 years each. The cumulative discoveries durng this period amounted to about $136 \times 10^{9}$ barrels.

The most significant fact pointed out by this figure is that during the first penod when onl was easy to find the discoveries averaged 194 barrels per foot. During the second period, extending from 1920 to 1928 , the discovery rate dropped to 167 barrels per foot, indicating that oll was getting more difficult to find Then, during the third period extending from 1928 to 1937 , the peak rate of 276 barrels per foot was achieved. This was due jointly to the accidental discovery of the 6-billion-barrel Edst Texas field and to the development of superior geophysical methods of well logging and exploration. From 1937 to 1965 the figure shows a spectacular decline in discovenes per foot to an dverage rate for the last few intervals of only about 35 barrels per foot.

The fact that this decline in the effectiveness of exploratory activities occurred during the period of the most intensive research and development of improved methods of petroleum exploration and production can hardly have any other significance than that the diminishing supply of undiscovered oil is becoming increasingly difficult and expensive to find.

About as liberal an extrapolation of this decline curve into the future as can be justified by the data gives an estimate of about 165 billion barrels as the ultimate amount of oll, producible by present technology, that may be expected to be discovered in the conterminous 48 states and their adjacent continental shelves If this figure is approximately correct, then the 136 billion barrels discovered up to 1966 would represent about $82 \%$ of that ultimately to be discovered.

In contrast with this estimate of $165 \times 10^{9}$ barrels based on the data of Fig 14 , mention should also be made of an estimate of $590 \times 10^{9}$ barrels for the same ared made in 1961 by the late A. D. Zapp of the U.S Geological Survey. ${ }^{6}$ Zapp's estimate was based on the hypothesis illustrated graphically in Fig. 15. Zapp stated that petroleum exploration in the United States could not be regarded as completed until a density of exploratory wells of about one well to each 2 square miles had been drilled to depths either to the bottom of the sediments or to $20,000 \mathrm{ft}$ in all petroleum-bearing areas In $1959 \mathrm{Zapp}^{6}$ estumated that this amount of drilhng for all the potential petroleum-bearing basins in the United States exclusive of Alaska would amount to $5 \times 10^{9} \mathrm{ft}$, whereas at that time the cumulative exploratory drilling amounted to an estimated $0.98 \times 10^{9} \mathrm{ft}$. Zapp further stated that there was no evidence that any decline had yet occurred in the oll discoveries per foot, and he assumed that this would continue to be true for the future $4 \times 10^{9} \mathrm{ft}$ of exploratory drilling. He accordingly estimated that by 1959 the United States was less than $20 \%$ along in its petroleum exploration, yet had already discovered over $100 \times 10^{9}$ barrels of oll. This implied that the ultimate figure would be more than $500 \times 10^{9}$ barrels. In 1961 Zapp gave the definite figure of $590 \times 10^{9}$ barrels. This would require an average discovery rate of 118 barrels per foot for the postulated $5 \times 10^{9} \mathrm{ft}$ of drilling, a rate equal to the estımated discoveries per foot up to 1961 


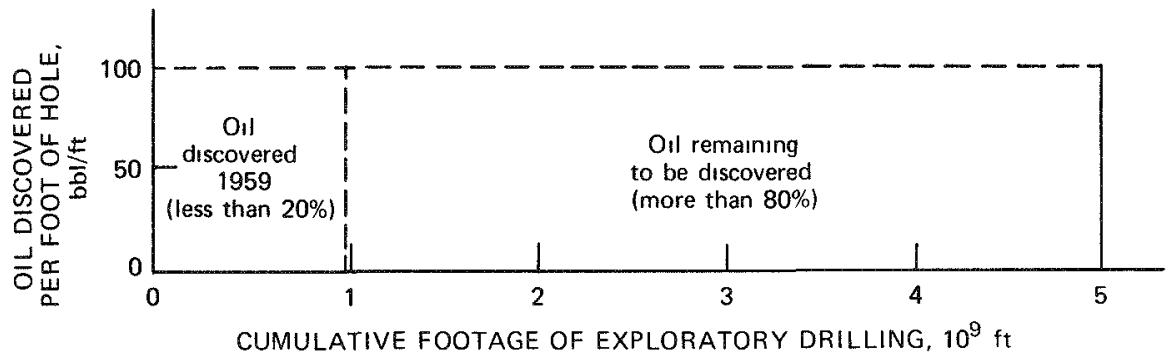

Fig. 15 Graphical representation of Zapp's hypothesis ${ }^{6}$ of oll discoveries per foot of exploratory drilling vs. cumulative footage. ${ }^{2}$

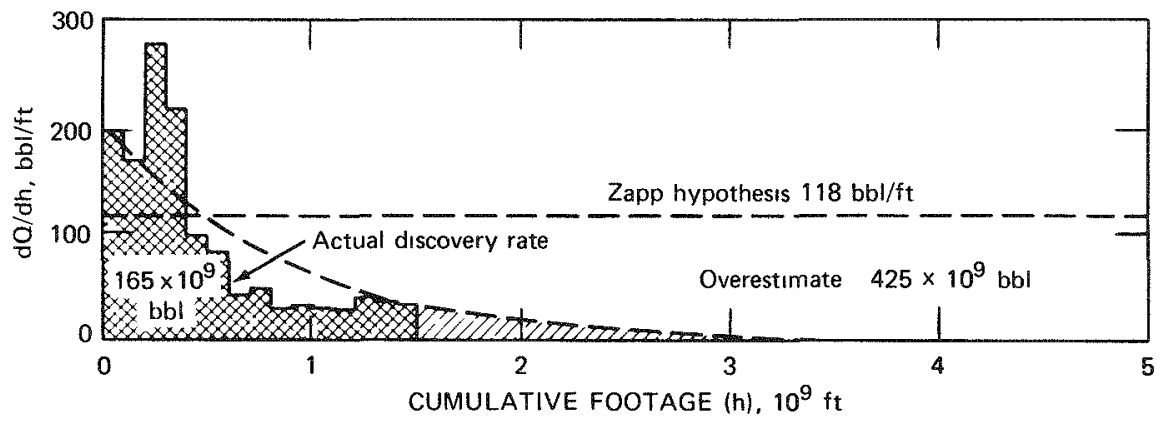

Fig. 16 Comparison of actual U. S. discovery rate shown in Fig. 14 with that predicted by Zapp's hypothesis in Fig. 15 (Ref. 2).

Zapp's hypothesis is especially significant because the estimate for the ultimate U S crude-oil resources to which it led was about $1 \frac{1}{2}$ times the highest previously published estimates and $3 \frac{1}{2}$ times the present figure of $165 \times 10^{9}$ barrels derived from the data of over a century of petroleum exploration and production. Also, either in its onginal form or in slight modifications, this hypothesis continues to be the principal basis for most of the higher estimates for the ultimate amounts of oll and gas to be produced.

Fortunately, the validity of the hypothesis is amenable to testıng against petroleum-industry data. The oil discovenes per foot of exploratory drilling during the past century, as shown in F1g. 14, have not been substantially constant, as assumed by Zapp, but have declined drastically during the last 30 years. Also the data do not afford any basis for the further assumption that the oil discoveries per foot in the future will remain substantially constant and equal to the average value during the past. A direct comparison between Zapp's hypothesis, based on an average discovery rate of 118 barrels per foot of exploratory drilling, and the actual discovery data of Fig. 14 is shown by superposition in Fig. 16. The blank area between the two curves represents $425 \times 10^{9}$ barrels, which appears to be the approximate magnitude of the Zapp overestımate. 


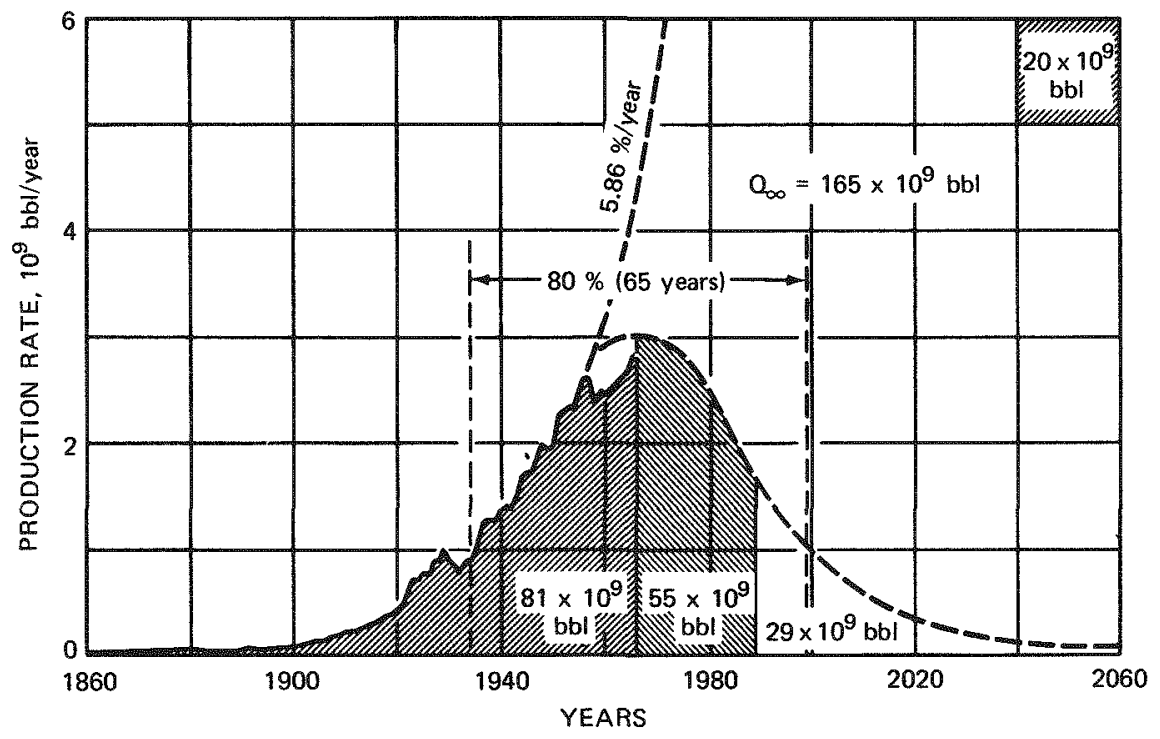

Fig. 17 Complete cycle of U. S. crude-oll production, exclusive of Alaska. ${ }^{2}$

Using our estimate of $165 \times 10^{9}$ barrels for $Q_{\infty}$ for the conterminous United States and its adjacent continental shelves, we can construct the approximate curve for the complete production cycle of crude oil for this area (Fig. 17). This curve indicates that the production peak should occur very close to the year 1970. This figure was constructed on data extending only through 1965. Subsequently the production curve, plotted weekly, has steadily risen to a peak at about November 1970, after which it has steadily declined ( $\mathrm{Oll}$ and Gas Journal, weekly statistics section). This date may prove to be that of the ultimate production peak of crude oll for the conterminous United States.

As with coal, the dashed curve in Fig. 17 extending to the top of the chart indicates what the production rate would be if it continued at the growth rate of $586 \%$ per year which prevailed from about 1933 to 1955 The vertical dashed lines at the years 1933 and 1998 represent the approximate dates at which the cumulative production reaches $10 \%$ and $90 \%$, respectively, of $Q_{\infty}$. The period during which the middle $80 \%$ will be consumed w1ll accordingly be that of the 65 years between these two dates. In other words, about $80 \%$ of the ultimate amount of crude on produced in the conterminous United States will probably be consumed within the average lifetime of people born in 1930

The ultimate quantity, $\mathrm{Q}_{\infty}$, for the cumulative production of natural gas in the conterminous United States may be estimated in various ways (1) by compiling estimates based on the geology and production records of separate gas-producing areas, (2) by an analysis of the discovery and production statistics as a function of time, or 


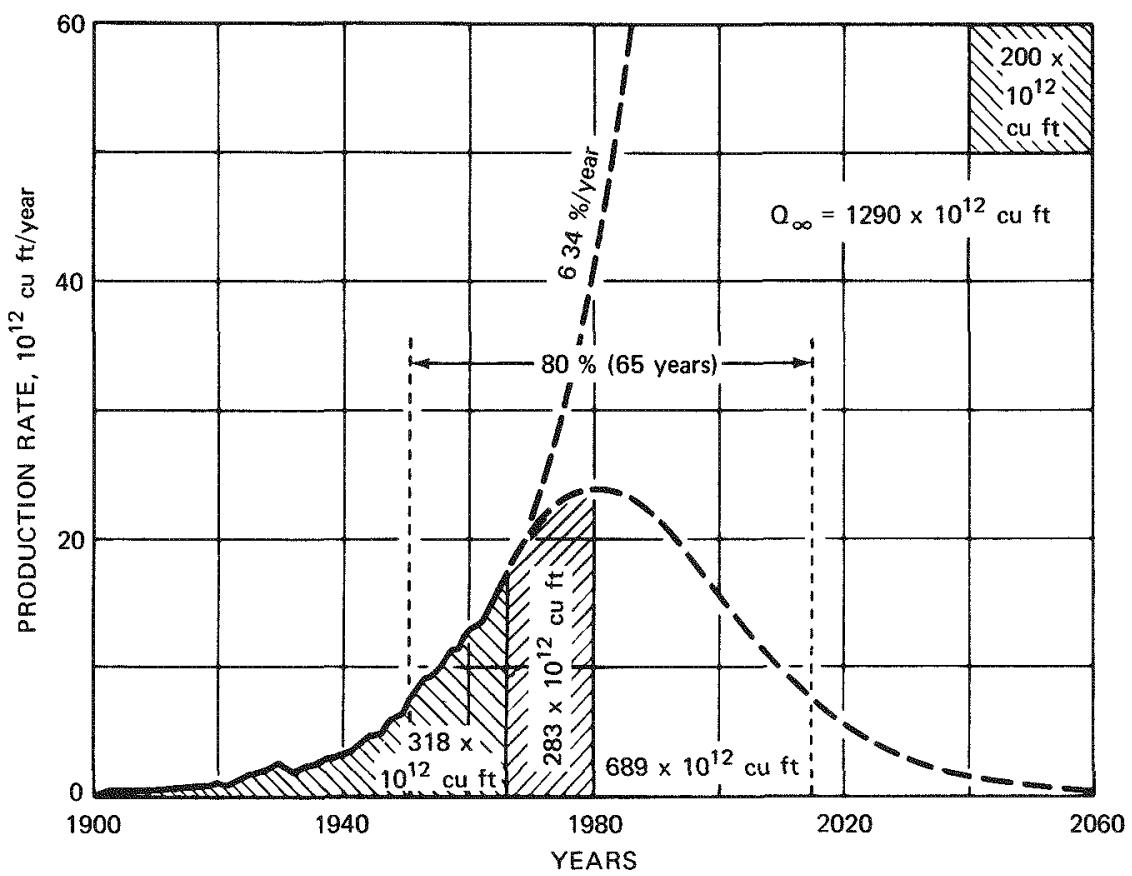

Fig. 18 Complete cycle of U.S. natural-gas production (Alaska excluded). ${ }^{2}$

(3) from previous estimates of the ultimate cumulative discoveries of crude oll in conjunction with the ratio of gas to oil discoveries

The first of these methods is that used by the Potential Gas Committee, an industry committee that comples biennial estimates based partly on unpublished industry data Figure 18 shows the complete cycle of natural-gas production in the contermmous United States and adjacent continental shelves based on an estimate for $\mathrm{Q}_{\infty}$ of $1290 \times 10^{12} \mathrm{cu} \mathrm{ft}$ made by the Potentual Gas Committee ${ }^{7}$ in its 1967 report giving data as of Dec 31, 1966 As shown in Fig 18, this value of $Q_{\infty}$ implies that the rate of production will not reach its peak before about 1980

In its October 1969 report, ${ }^{8}$ giving estımates as of Dec 31, 1968, this Committee increased its estimate for the conterminous United States including the adjacent continental shelves and slopes to a depth of $1500 \mathrm{ft}$ to $1427 \times 10^{12} \mathrm{cu} \mathrm{ft}$ It may be noted, however, that, of the estumate of $1290 \times 10^{12} \mathrm{cu} \mathrm{ft}, 180 \times 10^{12}$ was classed as "speculative" and, of the $1427 \times 10^{12} \mathrm{cu} \mathrm{ft}$, about $240 \times 10^{12}$ was classed as "speculative."

A direct analysis of natural gas based on its drilling, discovery, and production statistics has not been made, but an approximate estimate can be made from our previous value of $165 \times 10^{9}$ barrels as the value of $Q_{\infty}$ for crude oil and from the gas-to-o1l ratio By Dec 31, 1970, the cumulative proved discoveries of crude oil in the conterminous United States and adjacent continental shelves amounted to $122 \times 10^{9}$ 
barrels At the same time, the cumulative discoveries of natural gas amounted to $648 \times 10^{12} \mathrm{cu} \mathrm{ft}$ Therefore, the ratio of cumulative discoveries of gas to those of orl amounted to $5320 \mathrm{cu}$ ft per barrel However, it is known that this ratio is increasing with time owing largely to the fact that with incredsing depth of drilling the gas-to-oll ratio increases For the discoveries during the last few years, it averages about $6500 \mathrm{cu}$ $\mathrm{ft}$ per barrel Therefore, for a rough estımate let us make the liberal assumption that, for all future discoveries of oil and gas, the gas-to-oll ratio will be $7500 \mathrm{cu} f t$ per barrel

Using the figure of $165 \times 10^{9}$ barrels as the ultimate amount of crude ol to be discovered and the figure of $122 \times 10^{9}$ barrels as the cumulative proved discoveries, we obtain $43 \times 10^{9}$ barrels as the amount of crude oll still to be added to cumulative proved discoveries At $7500 \mathrm{cu} \mathrm{ft}$ per barrel, this gives an estımate of $323 \times 10^{12} \mathrm{cu} \mathrm{ft}$ of natural gas still to be discovered Adding this to the $648 \times 10^{12} \mathrm{cu}$ ft already discovered then gives $971 \times 10^{12} \mathrm{cu} \mathrm{ft}$, or roundly $1000 \times 10^{12} \mathrm{cu} \mathrm{ft}$, as a rough estimate for $Q_{\infty}$ for natural gas

A curve of the complete cycle of natural-gas production based on this lower figure would give an earlier date of around 1973 to 1976 for the peak in the rate of production The fact that serious gas shortages are already beginning to occur in the United States affords some grounds for thinking that the estımates of the Potential Gas Committee may be considerably too high and that the smaller figure of around 1000 trillion cubic feet may be a better estimate

The oll and gas potentials of Alaska have not been treated with those of the conterminous United States because Alaska is a new territory that has not yet made significant contributions However, since 1958 several medium-sized orl fields have been discovered and have become productive in the Kena1 Peninsula and Cook Inlet in southwest Alaska. On the Alaskd north slope the unproductıve Umiat field was discovered in 1947 and confirmed by further drilling in 1950 in U S Naval Petroleum Reserve No 4 In 1968 the discovery of the large Prudhoe Bay field was announced Its presently estimated reserves of $10 \times 10^{9}$ barrels make 1 the largest onl field in the United States

Only crude preliminary estimates can yet be made as to the ultimate amounts of oll and gas that Aldska will produce, but, from present geological and discovery information, it appears that these amounts will probably not be less than $30 \times 10^{9}$ barrels of crude oil, $180 \times 10^{12} \mathrm{cu} \mathrm{ft}$ of natural gas, and $6 \times 10^{9}$ barrels of natural-gas liquids Although the discovery of a 10-billon-barrel oil field has produced a considerable amount of enthusiasm, it should be noted that a field of this size is less than a 3-year supply for the U S requirements, and 30 billion barrels of oll and 180 trillion cubic feet of gas offer less than a 10 year supply

Estımates of the ultimate amount of crude on to be produced in the entire world are made largely by geological comparisons between the better known areas, such as the United States, and less developed areas Such estimates range at present from about 1350 to $2100 \times 10^{9}$ barrels The higher figure is that given in 1967 by W P Ryman of the Standard O1l Company of New Jersey at a conference of the National Academy of Sctences-National Research Council Committee on Resources and Man ${ }^{2}$ The smaller figure represents about the lower limt of present estimates 


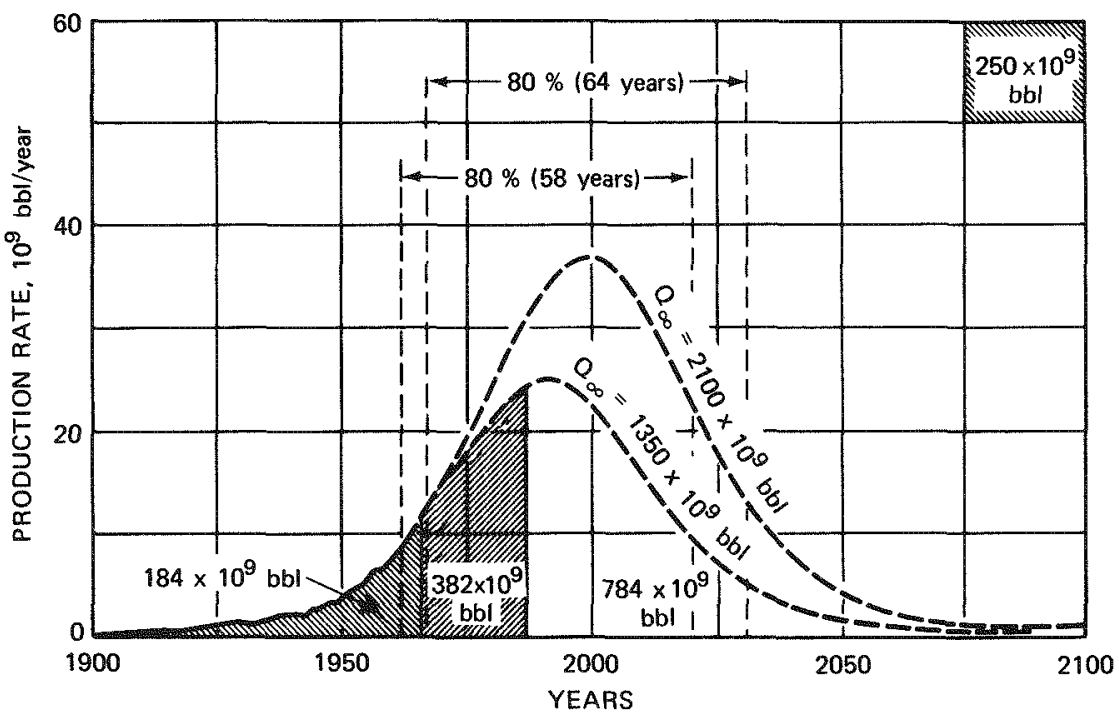

Fig. 19 Complete cycle of world crude-oil production for two values of $\mathrm{Q}_{\infty}{ }^{2}$

The complete cycle of world crude-oil production based on these two figures for $\mathrm{Q}_{\infty}$ is shown in Fig. 19. For the higher figure, the production rate would reach a maximum by about the year 2000; for the smaller figure, by about 1990. In both curves the middle $80 \%$ of $\mathrm{Q}_{\infty}$ would be produced in a time span of between about 58 and 64 years.

\section{FOSSIL FUELS IN HISTORICAL PERSPECTIVE}

Time does not permit us to review in detail all classes of fossil fuels, such as the world supply of natural gas, natural-gas liquids, tar sands, and oil shales. However, the estimated relative magnitudes of the world resources of these different classes of fuels are shown in Table 1. Nearly $89 \%$ of the energy content of the fossil, fuels is represented by coal and lignite, and close to $5 \%$ each by petroleum liquids and natural gas, with only about $1.3 \%$ accounted for by shale and tar-sand oil. Consequently, the picture that we have drawn for both the United States and the world will not be significantly changed by a more detailed account. In any case, it appears likely that the world will consume the bulk of its initial supplies of petroleum resources within a period of less than a century and the bulk of its coal and lignite within three or four centuries.

Lest three or four centuries may appear to be a long time, it may help if we view this episode of the fossil fuels in the context of a longer span of human history. This 
Table 1

ENERGY CONTENTS OF THE WORLD'S INITIAL SUPPLY OF FOSSIL FUELS ${ }^{3}$

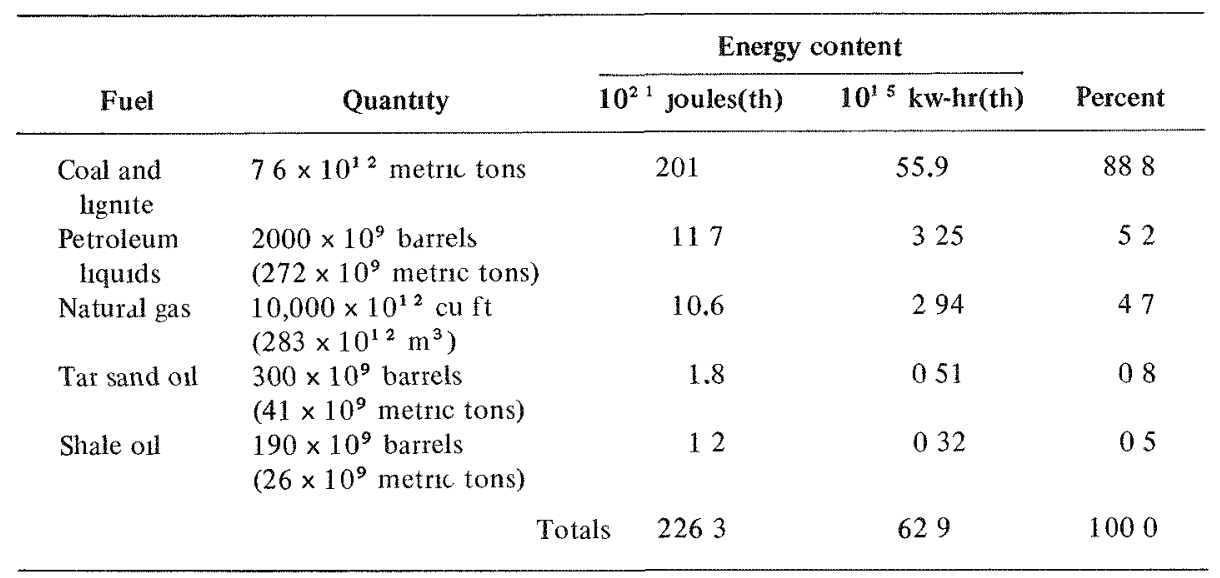

we may do if we plot the complete cycle of the consumption of the fossil fuels on a time base extending from 5000 years in the past to 5000 years in the future. The result, as shown in Fig 20, is a curve that rises from near zero to a sharp crest and then returns to near zero in the narrow span of about one-third of a millennium On such a time scale, it is seen that the entire epoch of the fossil fuels can be only a transitory and ephemeral event in human history - an event, nonetheless, which is unique in geological history and which has exercised the most drastic influence experienced by the human species during its entire biological history

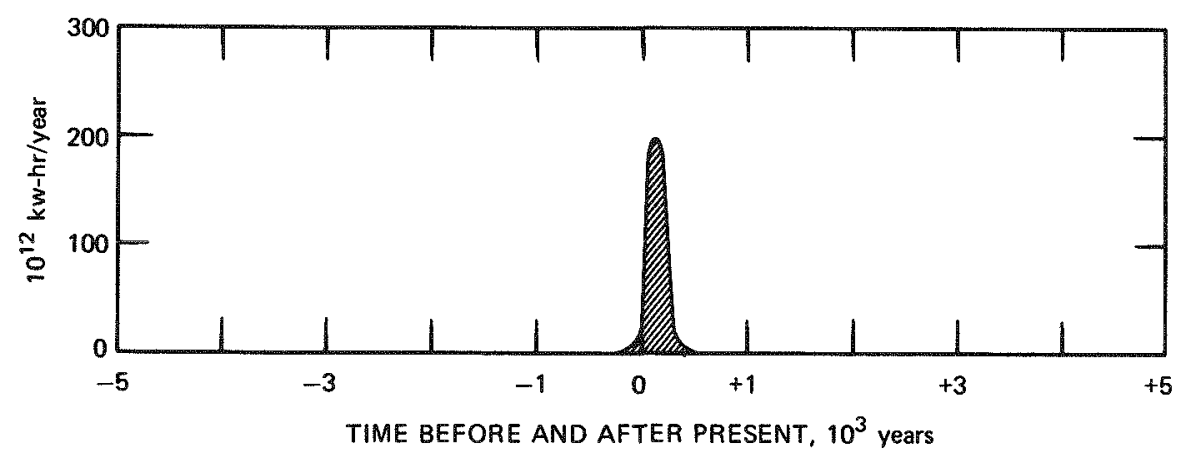

Fig. 20 Complete cycle of world consumption of fossil fuels on a tıme scale of 5000 years before and after the present. (Modified from Ref. 2.) 


\section{OTHER SOURCES OF INDUSTRIAL ENERGY}

\section{Solar Power}

Figure 2 shows that the largest source of energy avalable to the earth is the solar radiation intercepted by the earth. This power amounts to about $178,000 \times 10^{12}$ watts, or, if we disregard the $35 \%$ that is reflected directly into outer space, to about $116,000 \times 10^{12}$ watts absorbed and utllized in the various terrestrial processes. This latter figure amounts to about 20,000 times the present world rate of use of industrial energy. In addition, solar energy is pollution free and has an expectable time span comparable to that of the age of the earth.

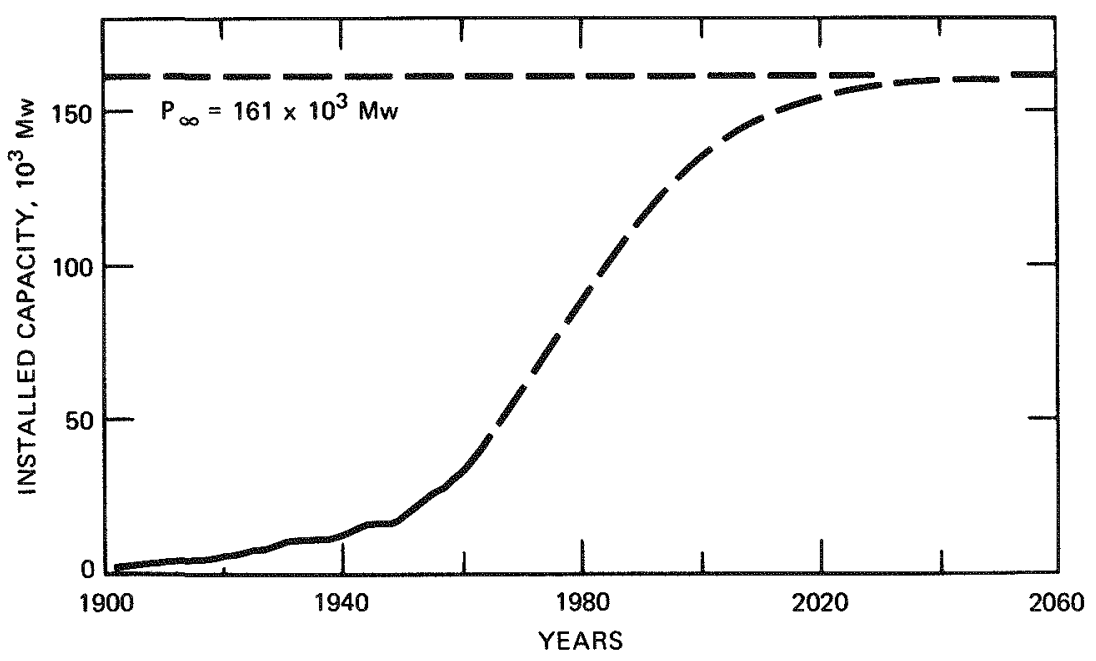

Fig. 21 U. S. installed and ultimate hydroelectric power capacity. ${ }^{2}$

At present the principal function of solar energy is to maintain the earth's moderate climate, to impel its material circulations, and by means of photosynthesis to provide the biological requirements of energy for the plant and animal kingdoms Until now the only channel of this contemporary energy flux, other than photosynthesis, which occurs in a concentrated form and is thus suitable for large-scale power development is water power from the hydrologic cycle The magnitude of the potential water-power capacity of the United States and its degree of development are shown in F1g. 21. The estimated ultimate capacity, $\mathrm{P}_{\infty}$, is $161 \times 10^{3}$ megawatts (Mw) of which about $50 \times 10^{3} \mathrm{Mw}$ is now developed

The potential water-power capacity of the major geographical land areas of the world and the degree of development of each are shown in Table 2. The total capacity is about $2900 \times 10^{3} \mathrm{Mw}$, or just under $3 \times 10^{12}$ watts of this, only about $85 \%$ is 
Table 2

WORLD POTENTIAL AND DEVELOPED WATER-POWER CAPACITY ${ }^{3}$

\begin{tabular}{|c|c|c|c|c|}
\hline Region & $\begin{array}{c}\text { Potential power, } * \\
10^{9} \text { watts }\end{array}$ & $\begin{array}{l}\text { Percent of } \\
\text { total }\end{array}$ & $\begin{array}{c}\text { Developed } \uparrow \\
\text { capacity, } 1967, \\
10^{9} \text { watts }\end{array}$ & $\begin{array}{c}\text { Percent } \\
\text { developed }\end{array}$ \\
\hline North America & 313 & 11 & 76 & 23 \\
\hline South America & 577 & 20 & 10 & 17 \\
\hline Western Europe & 158 & 6 & 90 & 57 \\
\hline Africa & 780 & 27 & 5 & 06 \\
\hline Middle East & 21 & 1 & 1 & 48 \\
\hline Southeast Asta & 455 & 16 & 6 & 13 \\
\hline Far East & 42 & 1 & 20 & 48 \\
\hline Australia & 45 & 2 & 5 & 11 \\
\hline $\begin{array}{l}\text { USSR, China } \\
\text { and satellites }\end{array}$ & 466 & 16 & 30 & 64 \\
\hline World & 2857 & 100 & 243 & 85 \\
\hline
\end{tabular}

*Francis L Adams, U S Federal Power Commission, Statement on water power to Committee on Natural Resources, National Academy of Sciences, unpublished 1961

†U S Federal Power Commission, World Power Data 19671969

now developed-principally in the highly industrialized areas of North America, Western Europe, and the Far East, especially Japan Among the areas with the largest potential water-power capacities are the industrially underdeveloped regions of Africa, South America, and Southeast Asia, whose combined capacities represent about $63 \%$ of the world total

The logistic growth curve of the world's developed and potential water power is shown in Fig 22 If fully developed, the $3 \times 10^{12}$ watts of water power would be of approximately the same magnitude as the world's present rate of industrial power use It might also appear that this would be an inexhaustible source of power, or at least one with a time span comparable to that required to remove mountains by stream erosion This may not be true, however Most water-power development involves the creation of reservoirs through the damming of streams The time required to fill these reservoirs with sediments is only two or three centuries Hence, unless a technical solution can be found for this problem, water power may actually be comparatively short lived

The remaining prospect for the large scale industral use of solar energy is that of its conversion to conventional electric power or for such chemical uses as the separation of chemical compounds into their component elements by electrolysis Heretofore the principal difficulty in developing large-scale power from solar radiation has resulted from the low areal density of solar radiation on the earth's land surfaces The most promising areas dre those of low rainfall lying within a belt of about \pm 35 degrees of latitude The land areas satisfying these conditions are very large They comprise a band in the southwestern United States, most of northern Mexico, a large 


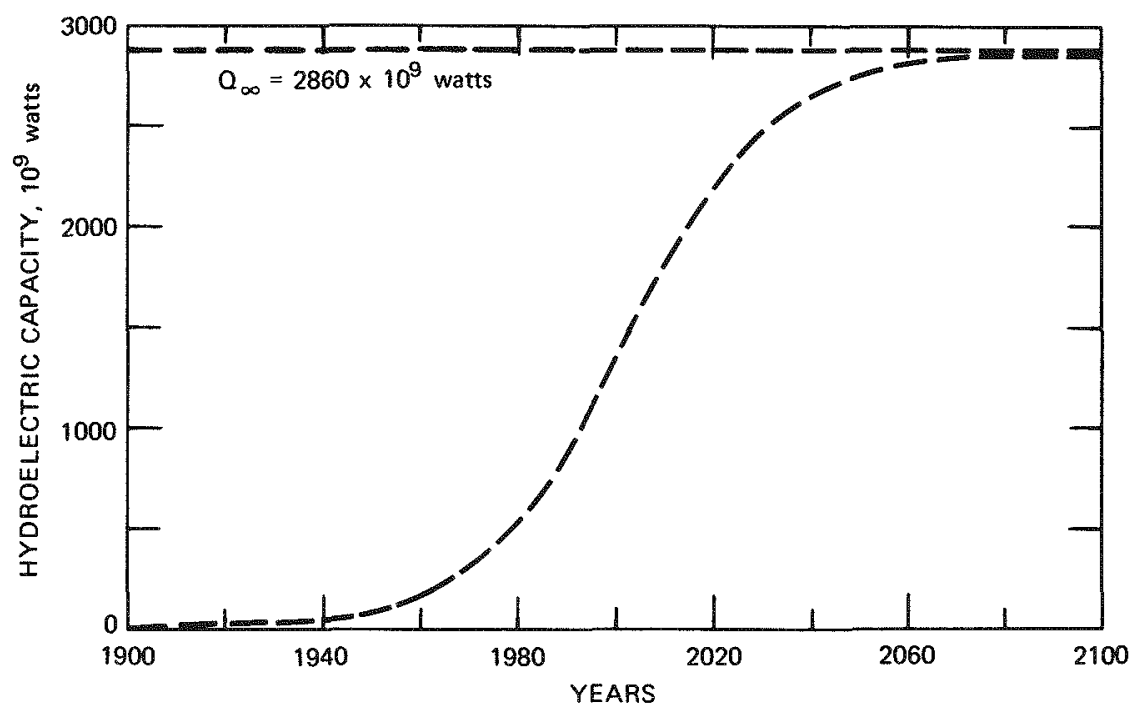

Fig. 22 Potential and developed hydroelectric capacity of the world.

coastal belt in Peru and Chile, and a band that includes the Sahara Desert and extends across northern Africa, the Red Sea area and the Arabian Peninsula, the Persian Gulf, Southern Iran, and West Pakıstan.

For one such area, consider southern Arizona. Here the average solar energy incident upon a horizontal surface changes from a winter minimum of 300 to a summer maximum of 650 , with a yearly average of $500\left(\right.$ calones $\left./ \mathrm{cm}^{2}\right) /$ day. Restricting ourselves to the winter minimum, 300 (calones $/ \mathrm{cm}^{2}$ )/day, when averaged over $24 \mathrm{hr}$, is equivalent to 145 watts per square meter, or to 145 thermal megawatts $[\mathrm{Mw}(\mathrm{th})]$ per square kilometer. Now suppose that by means of photovoltalc cells with a $10 \%$ efficiency enough solar energy were to be collected for a power plant of 1000 electrical megawatts $[\mathrm{Mw}(\mathrm{e})]$ capacity, what would the collection area have to be? This would require $10,000 \mathrm{Mw}$ of solar energy, which, at a rate of $145 \mathrm{Mw} / \mathrm{km}^{2}$, would require a collection area of about $70 \mathrm{~km}^{2}$, or a square of $8.4 \mathrm{~km}$, or $5 \mathrm{mlles}$, to the side. For the same region the area required to produce the $350,000 \mathrm{Mw}(\mathrm{e})$, which was approximately the electrical power capacity of the United States in 1970, would be about $24,500 \mathrm{~km}^{2}$, or about 9460 square miles, which is less than $10 \%$ of the total area of Arizona.

Hence, although solar power is intermittent and of low areal density, its magnitude when integrated over comparatively small areas becomes surprisingly large. When it is considered that solar power is almost pollution free and is best developed in sparsely vegetated and populated regions and when the complexities of a solar-power plant are compared with one operated by coal, it may well be that such plants are not as technically impractical as they at first appear In any case, it is significant that, 
principally withm the last few years, a continuously increasing amount of study by highly competent scientists, engineers, and research institutions is being devoted to the possibility of developing solar power on an industrial scale.

\section{Tidal and Geothermal Power}

Only brief attention can be given to the development of power from the tides and from geothermally generated steam. Tidal power is similar to water power except that

Table 3

TIDAL-POWER SITES AND MAXIMUM POTENTIAL POWER * $\dagger^{3}$

\begin{tabular}{|c|c|c|}
\hline $\begin{array}{l}\text { Locality } \\
\text { or region }\end{array}$ & $\begin{array}{c}\text { Average } \\
\text { potential power, } \\
10^{3} \mathrm{kw}\end{array}$ & $\begin{array}{c}\text { Potentual annual } \\
\text { energy production, } \\
10^{6} \mathrm{kw}-\mathrm{hr}\end{array}$ \\
\hline \multicolumn{3}{|l|}{ North America* } \\
\hline Bdy of Tundy (nine sites) & 29,027 & 254,445 \\
\hline \multicolumn{3}{|l|}{ South America } \\
\hline Argentina, San Jose & 5,870 & 51,455 \\
\hline \multicolumn{3}{|l|}{ Europe } \\
\hline Fngland, Severn & 1,680 & 14,726 \\
\hline \multicolumn{3}{|l|}{ France } \\
\hline $\begin{array}{l}\text { USSRT } \\
\text { (four sites) }\end{array}$ & 16,049 & 140,682 \\
\hline & 63,775 & 559,038 \\
\hline
\end{tabular}

*N. W Trenholm, Canada's Wastıng Asset-Tidal Power, Elec Eng. News, 70(2) 52-55 (1961)

$\dagger$ L. B Bernshtein, Tidal Energy for Electric Power Plants (English translation of Russian original), IPST No 1205, Isrdel Program for Screntufic Translations, 1965, Table 5 5, p 173

It must be developed from the alternate filling and emptying of tidal basins, whereas water power is derived from the unidirectional flow of streams. Tidal power is only practical in coastal configurations where a combindtion of high tidal amplitudes and bays or estuanes amenable to being enclosed by dams exists.

Table 3 summarzes the world's more favorable tidal-power sites The power capacities of individual sites range from 2 to $20,000 \mathrm{Mw}$ each The world total of such sites as presently estimated amounts to about $63,000 \mathrm{Mw}$, which is only about $2 \%$ of the world's water-power capacity.

The world's first large-scale tidal-power plant is that on the La Rance estuary on the English Channel codst of France. It began operation in 1966 with an initial power of $240 \mathrm{Mw}$ and a planned enlargement to $320 \mathrm{Mw}$. 
Up to the present, geothermal power has been derived from natural steam generated in volcanic areas where elevated temperatures occur at comparatively shdlow depths Geothermal power has been produced in the Larderello region of Tuscany in Italy since 1904 and recently in the Monte Amrata region about $70 \mathrm{~km}$ to the southeast The total capacity of these two areas amounted in 1970 to about $400 \mathrm{Mw}$ In Warrake, New Zealand, drilling for geothermal steam was begun about 1950, and power-plant operation started in 1958 By 1970 the power capacity had reached only $160 \mathrm{Mw},{ }^{9}$ which is considerably less than the maximum capacity of $290 \mathrm{Mw}$ originally estimated for the area In the United States, at The Geysers in northern Californı, a $125 \mathrm{Mw}$ geothermal power plant began operation in 1960 Subsequently the power capacity in this area has been increased to a planned $192 \mathrm{Mw}$ by mid-1971 and $400 \mathrm{Mw}$ by 1973 Small geothermal plants also recently began operation in the USSR, Japan, and Mexico

At present, only an order-of magnitude estımate for the world's potential geothermal power can be given From a study of the known areas of volcanic heat appropnate for power production and the quantities of stored thermal energy, White $^{10}$ of the U S Geological Survey has estimated that there is enough geothermal energy to generate about $3 \times 10^{6} \mathrm{Mw}$ years of electrical energy $\mathrm{W}_{1}$ th a life expectancy of 50 yedrs, this would give an average electrical-power capacity for that length of time of about $60,000 \mathrm{Mw}$ This is about the same as the capacity of tidal power but only about $2 \%$ that of potential water power However, since geothermal power production is now only in its initial phase and since the total quantity of thermal energy at temperdtures above $100^{\circ} \mathrm{C}$ within depths of $10 \mathrm{~km}$ from the surface of the ground is much larger than the above figure, it is possible that a larger geothermal power capacity may eventually be achieved

\section{Nuclear Power}

We next direct our attention to the world's newest source of stored energy, the atomic nucles of some of the earth's natural constituents Nuclear energy is obtanable by two opposite types of nuclear reactions (1) the fissioning of certain isotopes at the heavy end of the scale of atomic masses and (2) the fusing into heavier elements of isotopes at the low end of the scale

Fission The only naturally occurring 1sotope which is capable of spontaneous fission under mild surface conditions is ${ }^{235} \mathrm{U}$, which occurs in natural uranium with an atomic abundance of 1 atom of ${ }^{235} \mathrm{U}$ to 141 atoms of uranium The remaning 140 atoms are of ${ }^{238} \mathrm{U}$

When ${ }^{235} \mathrm{U}$ is struck by a stray neutron, the neutron may be absorbed and cause the ${ }^{235} \mathrm{U}$ atom to fission, that is to divide into two roughly equal parts comprising two complementary atoms somewhere in the midrange of the atomic scale, plus one or more additional neutrons The average amount of energy released per fission of ${ }^{235} \mathrm{U}$ is about 200 million electron volts $(\mathrm{MeV})$, or $320 \times 10^{11}$ joules 


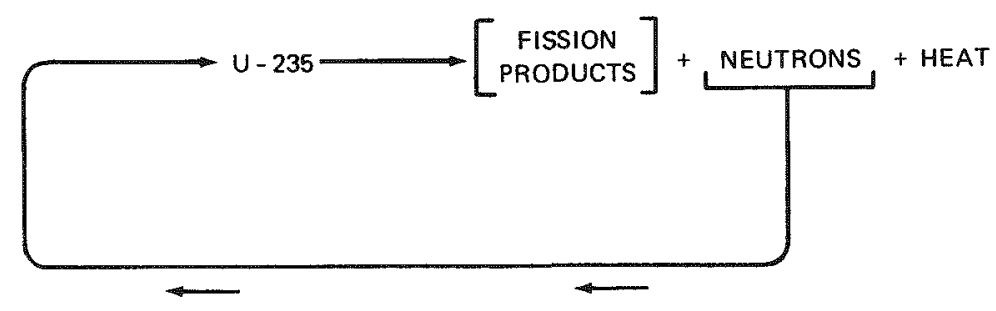

Fig. 23 Diagram of fission chan reaction. [From M. King Hubbert, Nuclear Energy and the Fossil Fuels, in Drlling and Production Practice (1956) p. 20, American Petroleum Institute, New York.]

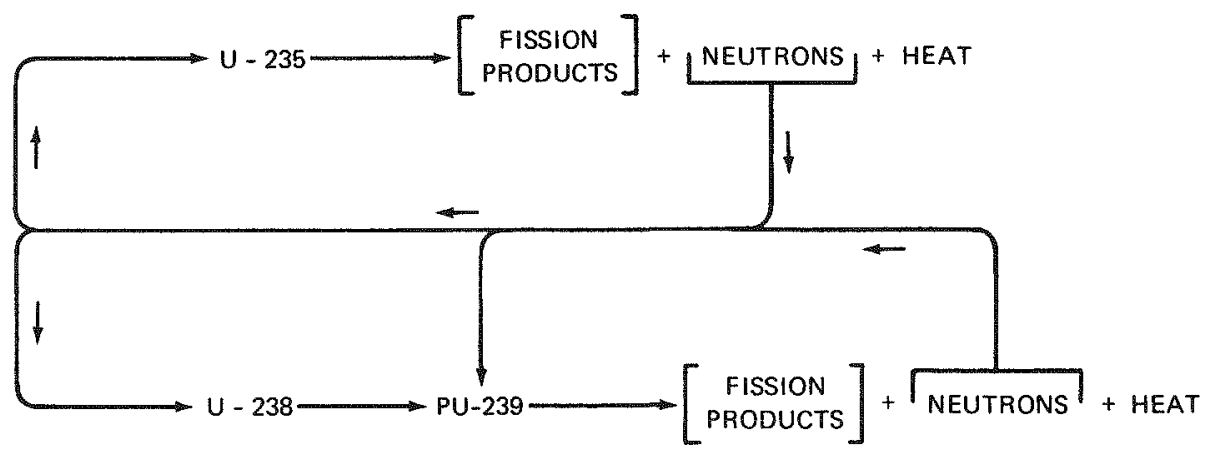

Fig. 24 Diagram of breeder reaction. [From M. King Hubbert, Nuclear Energy and the Fossil Fuels, in Drilling and Production Practice (1956) p. 20, American Petroleum Institute, New York.]

With a suitable drrangement of a ${ }^{235} \mathrm{U}$ fuel supply in a redctor a part of the neutrons released by fission are captured by other atoms of ${ }^{235} \mathrm{U}$, and a sustained, but controllable, chain reaction ensues This is shown didgrammatically in Fig 23

If ${ }^{238} \mathrm{U}$ or ${ }^{232} \mathrm{Th}$ (natural thorlum) is also placed in the reactor, either of them may dlso capture neutrons and then undergo successive radioactive transformations in this manner ${ }^{238} \mathrm{U}$ is converted into ${ }^{239} \mathrm{Pu}$, and ${ }^{232} \mathrm{Th}$ into ${ }^{233} \mathrm{U}$ Both ${ }^{239} \mathrm{Pu}$ and ${ }^{233} \mathrm{U}$ are fissile Thus, ${ }^{238} \mathrm{U}$ and ${ }^{232} \mathrm{Th}$, which are not themselves fissionable under ordinary circumstances, can be converted into fissionable materials They are therefore called fertile matenals The process of converting a fertile isotope into a fissile one is known as breeding A schematic diagram of the breeder reaction 1s given in Fig 24

The energy released per fission of ${ }^{235} \mathrm{U},{ }^{239} \mathrm{Pu}$, or ${ }^{233} \mathrm{U}$ is very nearly the same, namely, $200 \mathrm{MeV}$, or $320 \times 10^{11}$ joules The number of dtoms of ${ }^{235} \mathrm{U}$ per gram is $256 \times 10^{21}$, thus the fissioning of $1 \mathrm{~g}$ of ${ }^{235} \mathrm{U}$ would release $82 \times 10^{10}$ joules of heat Approximately the same amount of heat is released by the fissioning of $1 \mathrm{~g}$ of either ${ }^{239} \mathrm{Pu}$ or ${ }^{233} \mathrm{U}$ This is eqivalent to the heat of combustion of 27 metric tons of bituminous coal or of 134 barrels of crude ol 
In a reactor the heat released by nuclear fission is used to generate steam for a convantional steam-electnc power plant. Whether the energy obtamable from the nuclear fission reaction will be sufficient to take the place of that from the fossil fuels as these are depleted depends manly on two things (1) the existence of sufficient quantities of uranium and thorium in an economically extractable form and (2) the early development of breeder reactors. With regard to requirements, we should first take note of the fact that nearly all the power reactors now in use in the United States, as well as in the rest of the world, depend almost entirely on the rare isotope ${ }^{235} \mathrm{U}$.

By the end of 1970 the operable nuclear-power capacity in the United States, according to the Atomic Energy Commission, ${ }^{11}$ amounted to $6708 \mathrm{Mw}(\mathrm{e})$, and it is predicted to reach $150,000 \mathrm{Mw}(\mathrm{e})$ by 1980 . This would correspond to a grow th rate of $31 \%$ per year with a doubling period of only 2.3 years Nuclear-power capacity for the rest of the world is estimated to grow durnng this decade at about the same rate.

The projected U.S. requirements of uranium are estimated to amount to 206,200 short tons of $\mathrm{U}_{3} \mathrm{O}_{8}$ from 1971 to 1980 and another 452,100 short tons after $19800^{11}$ Aganst these requirements the ore reserves recoverable at $\$ 8$ per pound of $\mathrm{U}_{3} \mathrm{O}_{8}$ amounted at the end of 1970 to 243,000 short tons Although new discoveries will undoubtedly be added in the future, there is every indication at present that a severe shortage of ${ }^{235} \mathrm{U}$ will occur before the end of the present century. Hence, unless breeder reactors are rapidly developed, the eptsode of nuclear-fission power may be well past its climax within less than a century. With breeder reactors, however, the situation can be quite different because nuclear-fission power will no longer be dependent upon high-grade, low-cost sources of uranum but can be produced with the enormously larger quantitıes of low-giade ores.

A rough 1dea of the occurrence and distribution of both high- and low-grade ores of uranium and thorium in the United States may be ganed by reference to the map shown in Fig. 25. The high-grade deposits that are now mined are principally those of the Colorado Plateau. For a low-grade deposit, consider the Chattanooga shale. This is a black carbonaceous shale of Devonian age which crops out along the western edge of the Appalachian Mountains in eastern Tennessee and neighborng states and underlies at minable depths most of the areas of Tennessee, Kentucky, Ohio, Indiana, and Illinois. Its stratigraphic equivalent, the Woodford shale, also occurs in the subsurface of the mid-continent states. In the outcrop area of eastern Tennessee, the Chattanooga shale contans a stratum about $5 \mathrm{~m}$ thick, the Gassaway member, ${ }^{12}$ with a uranum content of about $60 \mathrm{~g}$ per metric ton. That the uranum-rich character of this shale is widespread is evident from the fact that when gdmma-ray logs are taken in oil wells even as far away as Texds and Oklahoma the instruments are driven off their scales when transversing the Woodford shale.

Let us consider the energy potentrally obtanable from the Chattanooga shale in eastern Tennessee by means of the breeder reactor. Bearing in mind that the energy 1eleasable from the fissioning of uranum amounts to the equivalent of that from 2.7 metric tons of coal or from 13.4 bdrrels of crude o1l, the $60 \mathrm{~g}$ of uranum per metric ton of shale would be approximately equivalent to 160 metric tons of coal or 800 barrels of crude oll. 
With a shale density of 2.5 metric tons per cubic meter, a vertical column $5 \mathrm{~m}$ long and $1 \mathrm{~m}^{2}$ in horizontal cross section would contain $750 \mathrm{~g}$ of uranium. This would be approximately equivalent energetically to 2000 metric tons of coal or to 10,000 barrels of crude oil per square meter of horizontal area. If we allow a loss of $50 \%$ of the uranium in mining and extraction, these figures would reduce to 1000 metric tons of coal or to 5000 barrels of crude oil per square meter, or to 1 billion metric tons of coal or 5 billion barrels of oil per square kilometer. Then, assuming $1500 \times 10^{9}$ metric

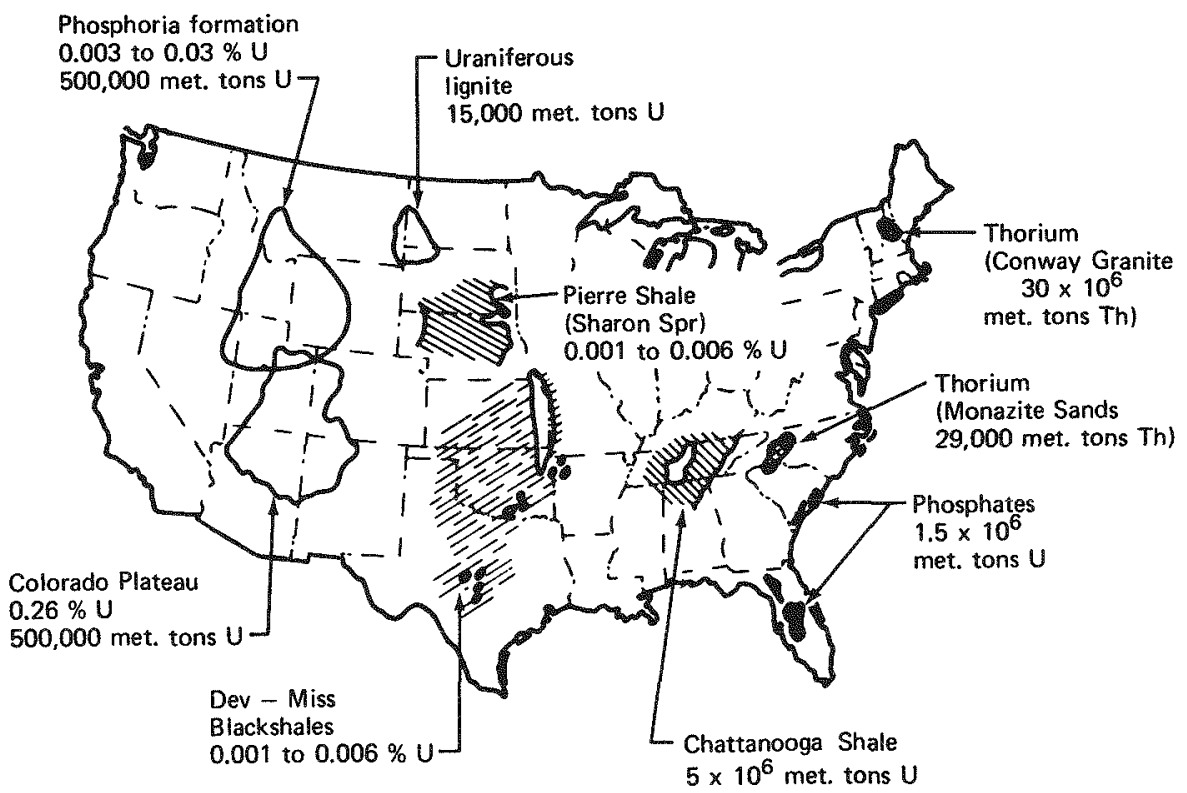

Fig. 25 Map showing the distribution of high- and low-grade ores of uranium and thorium in the United States. [Based on M. King Hubbert, Nuclear Energy and the Fossil Fuels in Drilling and Production Practice (1956), p. 23, American Petroleum Institute, New York.]

tons of coal and $500 \times 10^{9}$ barrels as the oil equivalent of petroleum liquids, natural gas, and shale oil, an area of only $1600 \mathrm{~km}^{2}$ would be required for the energy obtainable from the uranium in the Chattanooga shale in eastern Tennessee to be equal to that of the total supply of fossil fuels in the United States. This would be equivalent to a square area of $40 \mathrm{~km}$, or 25 miles, to the side, which would represent less than $2 \%$ of the area of Tennessee.

When the total areal extent of this uranium-rich shale is considered, it becomes evident that with breeder reactors the energy obtainable from the uranium of the Chattanooga shale alone is orders of magnitude larger than that of the total initial U.S. supply of fossil fuels. An even larger amount of potential nuclear energy is involved when other known low-grade sources of uranium and thorium, such as those shown on the map in Fig. 25, are also considered. 
Fusion. It has been known since 1939 that the continuous outpouring of energy from the sun and other stars is the result of a fusion reaction whereby the nucler of hydrogen atoms are combined to form those of heavier atoms of helium. In fact helium derives its name from the sun because it was detected spectroscopically in the solar atmosphere before it was identified on earth. Uncontrolled fusion has been achieved by man and is the basis for the so-called hydrogen, or thermonuclear, bomb. Intense research directed toward terrestrial attainment of controlled fusion has been under way in the United States, Great Britain, and the USSR for about 20 years, and progress is continuously being made, but this goal has not yet been achieved although there is hope that it may be within a few more decades.

A number of different fusion reactions are known. The one that is most favored at present involves the fusion of the two heavy isotopes of hydrogen, deuterium and tritium, of atomic masses 2 and 3 , respectively. ${ }^{13}$ Deuterium occurs in water with an atomic abundance of 1 atom of deuterium to 6700 atoms of common hydrogen. Tritium occurs naturally only in infinitesimal traces, so it has to be produced by the neutron bombardment of lithium.

Omitting intermediate steps, the deuterum-tritium, or D-T, reaction, beginning with deuterium and lithum, reduces to the following

$$
{ }^{2} \mathrm{D}+{ }^{7} \mathrm{Ll}+{ }^{6} \mathrm{Ll} \rightarrow 3{ }^{4} \mathrm{He}+{ }^{3} \mathrm{~T}+19.9 \mathrm{MeV}
$$

The limiting factor in this reaction is lithium and especially the isotope ${ }^{6} \mathrm{~L}$, which occurs with an atomic abundance of only $7.42 \%$ of natural lithium. Lithium is obtained on land from a rare type of igneous rock known as a pegmatite and from certain saline deposits. From the known and inferred occurrence of such deposits, it is estumated that the world supply of ${ }^{6} \mathrm{~L} 1$ amounts to about $67.5 \times 10^{33}$ atoms of this 1sotope. On the other hand, deuterium is obtanable from seawater, and the entire deuterium content of the oceans amounts to about $1.35 \times 10^{43}$ atoms.

From the D-T reaction $19.9 \mathrm{MeV}$ or $3.19 \times 10^{-12}$ joules of energy is released per atom of ${ }^{6} \mathrm{~L} 1$ consumed. Then, for the total supply of $675 \times 10^{33}$ atoms of ${ }^{6} \mathrm{~L} 1$, the total amount of energy released by fusion would be $215 \times 10^{21}$ joules This is approximately equal to the energy of the world's supply of fossil fuels.

Since deuterium is about $10^{8}$ times more abundant than ${ }^{6} \mathrm{~L} 1$, the more difficult deuterium-deuterium, or $\mathrm{D}-\mathrm{D}$, redction is potentially capable of releasing a very much larger quantity of energy. In this case, three separate reactions give the combined result

$$
5^{2} \mathrm{D} \rightarrow{ }^{4} \mathrm{He}+{ }^{3} \mathrm{He}+\mathrm{H}+2 n+24.8 \mathrm{MeV}
$$

Hence, the energy released per deuterium atom in the D-D fusion reaction is 4.96 $\mathrm{MeV}$ or $7.95 \times 10^{-13}$ joules

To obtain an 1dea of what this signifies, let us consider the deuterium content and hence the potential energy obtanable from 1 liter, or $1000 \mathrm{~g}$, of water. Since water 
has a molecular mass of $18 \mathrm{~g}, 1$ liter of water comprises 55.56 moles. One mole contains $6.022 \times 10^{23}$ molecules, and each molecule contans 2 hydrogen atoms Therefore 1 liter of water contains

$$
2 \times\left(6.022 \times 10^{23}\right) \times 5556=6.67 \times 10^{25} \text { hydrogen atoms }
$$

Since there is 1 atom of deuterium to 6700 atoms of hydrogen, we find that 1 liter of water must contain $10 \times 10^{22}$ atoms of deuterium, each of which by the D-D fusion reaction is capable of releasing $795 \times 10^{-13}$ joules of heat The total energy per hter would therefore be

$$
\left(10 \times 10^{22} \mathrm{D}\right) \times\left(795 \times 10^{13} \text { joules } / \mathrm{D}\right)=795 \times 10^{9} \text { joules }
$$

For comparison, the heat of combustion of bituminous coal is about $3.05 \times 10^{10}$ joules per metric ton, and that of crude oll, $61 \times 10^{9}$ joules per barrel Therefore, the energy of fusion of the deuterium in 1 liter of water would be equivalent to the heat of combustion of 026 metric tons of coal or to 1.30 barrels of crude onl. With these figures as a base, the fusion energy from various volumes of seawater and the equivalent quantities of coal and oil are computed in Table 4. It is interesting that the energy of a cubic kilometer of seawater is approximately equivalent to that of the world's initial supply of crude o1l, and the energy from $33 \mathrm{~km}^{3}$ is equivalent to that of the world's total initial supply of fossil fuels

\begin{tabular}{|c|c|c|c|}
\hline $\begin{array}{l}\text { Volume } \\
\text { of water }\end{array}$ & $\begin{array}{l}\text { Energy, } \\
\text { thermal joules }\end{array}$ & $\begin{array}{l}\text { Coal equivalent, } \\
\text { metric tons }\end{array}$ & $\begin{array}{c}\text { Crude oil } \\
\text { equivalent } \\
\text { barrels }\end{array}$ \\
\hline 1 liter & $7.95 \times 10^{9}$ & 026 & 1.30 \\
\hline $1 \mathrm{~m}^{3}$ & $795 \times 10^{12}$ & 260 & 1300 \\
\hline $1 \mathrm{~km}^{3}$ & $795 \times 10^{21}$ & $260 \times 10^{9}$ & $1300 \times 10^{9}$ \\
\hline $33 \mathrm{~km}^{3}$ & $262 \times 10^{23}$ & \multicolumn{2}{|c|}{$\begin{array}{l}\text { World's total supply of } \\
\text { fossil fuels }\end{array}$} \\
\hline
\end{tabular}

Table 4

Since the area of the ocean is 361 million $\mathrm{km}^{2}$ and its average depth $38 \mathrm{~km}$, its volume must be $137 \times 10^{9} \mathrm{~km}^{3}$ This is approximately 40 million times the volume of $33 \mathrm{~km}^{3}$ given in Table 4 as being equivalent in energy content to the fossil fuels if we assume the extraction of only $10 \%$ of the deuterum from seawater, this still represents an amount of energy roughly 4 million times that of the fossl fuels 


\section{THE INDUSTRIAL METALS}

Industrial energy cannot be used without machmery, and machnery is composed principally of industrial metals, such as iron, aluminum, copper, lead, and zinc We need, therefore, to take at least a cursory look dt a few of the principal industrial metals

A generalized flow didgram for the production of a metal is shown in Fig 26 Like the fossil fuels, metdls are obtained from naturally occurring concentrations of

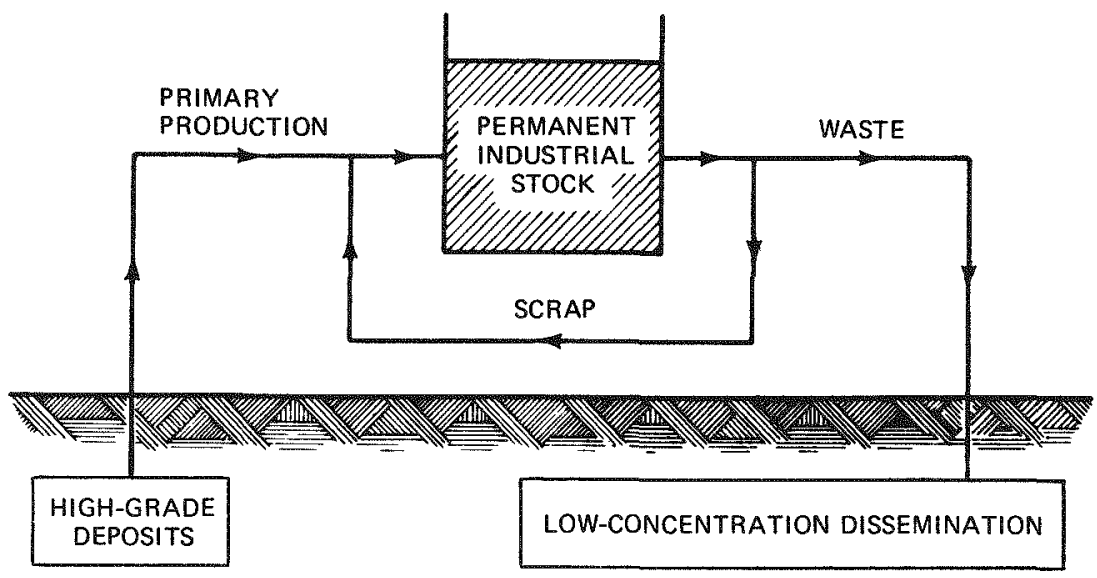

(THE GROUND)

Fig. 26 Flow diagram for the production and use of an industrial metal.

minerals comprising the ores of the various metals, many of which were formed by geological processes more than a billon years ago Unlike energy, which leaves the earth the metals are chemical elements which during their use are circulated but, with the trivial exception of spacecraft, do not leave the earth

The usual cycle for a metal begins with the mining of the metallic ore The metal is then extracted from the ore by some form of smelting, fabricated into a usable form, either metallic or chemical, and made a part of the industrial pool Finally, after having served its purpose, a fraction is recycled as scrap, refabricated, and returned to the industrial pool Another fraction, however, becomes irretrievably scattered or else rendered otherwise irretrievable as in the case of a ship that sinks in deep water For iron, the scrap that is recycled is prncipally obtained from heavy iron and steel products, whereas the wastage is principally by oxidation and the scattering of small items ranging from sheet iron cans to automobiles For lead, that which is used in metallic form, such as cable sheathing, and in automobile storage batteries, is retrieved and recycled, that which is used as oxides in pants and as tetraethyl lead in gasoline is scattered and lost 
The usual cycle for any given metal begins with a natural concentration of the chemical element in some kind of an ore body and eventually ends in a state of complete dispersion. The one exception to this sequence occurs when the initial state is not one of concentration but is instead a large low-concentration occurrence. A prime example is the extraction of magnesium from seawater. Here the metal is taken from the ocean, used, scattered, and eventually returned to the ocean. The quantity of magnesium contained in ocean water is so large compared with any industrial requirements that it is most unlikely that a measurable decrease in the magnesium

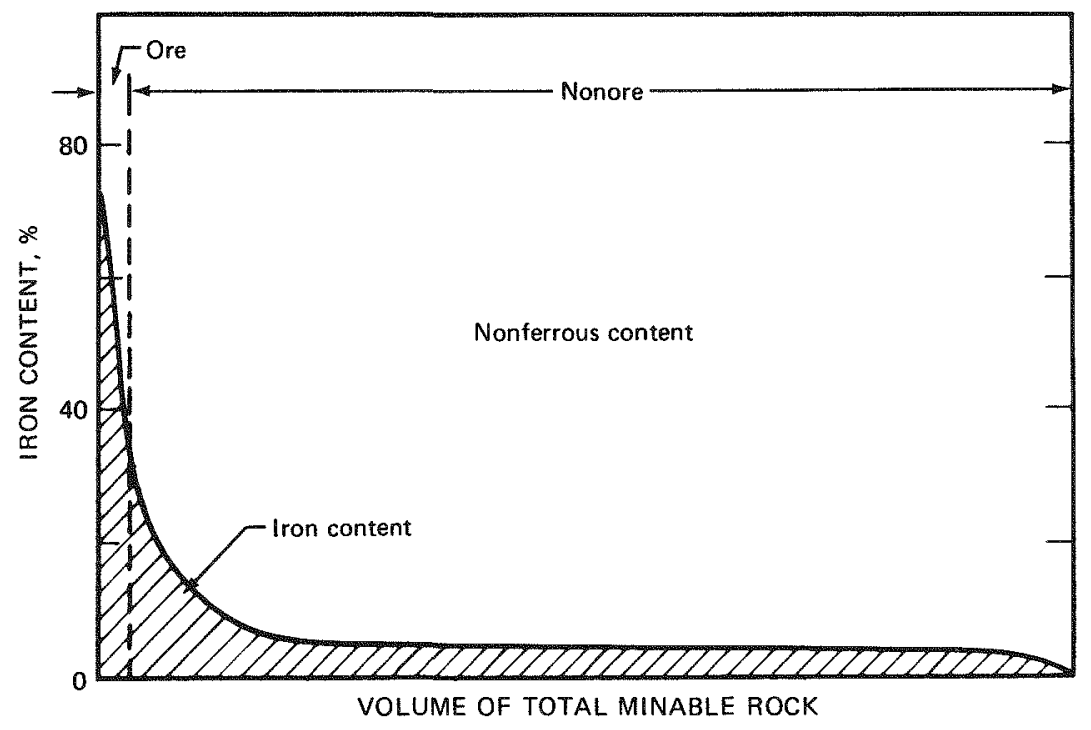

Fig. 27 Schematic diagram of the minable rock of the earth arranged in order of decreasing iron content. [From M. King Hubbert, Future Ore Supply and Geophysical Prospecting, Eng. Mining $J_{.}, 135: 19$ (1934).]

concentration in seawater will ever occur. In this system, it appears that we deal with a truly inexhaustible resource.

The approximate manner of occurrence of the various levels of concentration of a given metal in the minable rocks of the earth is represented diagrammatically in Fig. 27, using iron as an example. Chemical analyses of thousands of rock samples show that the average iron content of the rocks of the upper few kilometers of the earth is about $5.6 \%$. If we were to plot a graph in which the cumulative mass of all the rocks to a depth of, say, $10 \mathrm{~km}$ was the horizontal axis, and the percent of iron content was the vertical axis, then, descending from left to right, the graph would look something like that shown in Fig. 27. At the extreme left, the iron content would begin with a peak value of $72 \%$ corresponding to an iron ore of pure magnetite $\left(\mathrm{Fe}_{3} \mathrm{O}_{4}\right)$. It would then descend very steeply and level off to a broad plateau ranging 
from an iron content a little above to a little below the mean value of $5.6 \%$, and finally, at the extreme right, descend sharply to near zero.

The rock represented by the sharp peak at the left, principally that with an iron content of about $30 \%$ or more, represents the world's iron ores. Through mining, the ore represented by this peak is continuously removed, and the iron that it originally contained is transferred to the broad plateau of low iron concentration. From this it is clear that although a metallic element is not destroyed by use, the high-grade ores of such an element are both finite and exhaustible. Hence the metal must be obtained from rocks with progressively lower metallic contents and with corresponding increases of both physical and monetary costs for extraction, until eventually further mining is discontinued. This is illustrated in many of the mining districts of the world. For example, during the 18 th and 19 th centuries, Great Britain, utilizing domestic iron ores, was the leading iron producer in the world. Also, the ores of tin, copper, lead, and zinc in Cornwall had been exploited since Phoenician times. During the last half-century, however, Great Britain has become dependent upon imported iron ores, and the Cornish ores have now been largely depleted. ${ }^{14}$

In the United States, for nearly a century the iron mines of the Lake Superior district shipped iron ores with an average iron content of 50\%. By about 1950 these high-grade ores were largely exhausted, and production is now principally obtained from taconite ores with an iron content of but $30 \%$. For copper ores, the average copper content of the ores mined in the United States in 1922 was $1.7 \%$, or $34 \mathrm{lb}$ of copper per ton of rock. By 1968 this had declined to $0.6 \%$, or to but $12 \mathrm{lb}$ of copper per ton of rock. With lead and zinc, the Galena district of northwestern Illinois and southwestern Wisconsin and later the tri-state district of Missouri, Kansas, and Oklahoma were the leading producers of the country. By now both these districts have been virtually depleted.

The foregoing principles afford a basis for understanding the evolution of the metal-mining industries in any region. If high-grade ores are initially abundant, production tends to follow the customary exponential growth curves. As the higher grade ores are exhausted and lower grade ores are exploited, the growth rate slows down, and eventually the rate of production goes into a long decline. These principles are well illustrated by the production of industrial metals in the United States, of which we shall consider only iron, copper, lead, and zinc.

Fig. 28 is a graph of the U.S. production of pig iron from 1825 to 1958. Since iron and coal during most of this period represented the principal components of heavy industry, it is not surprising that the curves of pig-iron production and of coal production are so similar as to be barely distinguishable from one another. Both increased exponentially at annual rates of about $6.5 \%$ per year until about 1910 ; both broke sharply downward from this growth rate subsequently. This is seen even more clearly in Fig. 29 in which the pig-iron production is plotted semilogarithmically. It is significant that it was about the beginning of the present century that the United States became a net importer of both iron ore and pig iron.

Figure 30 shows the U. S. production of copper from domestic ores during the period 1850 to 1958. This also shows an exponential growth rate until about 1916 


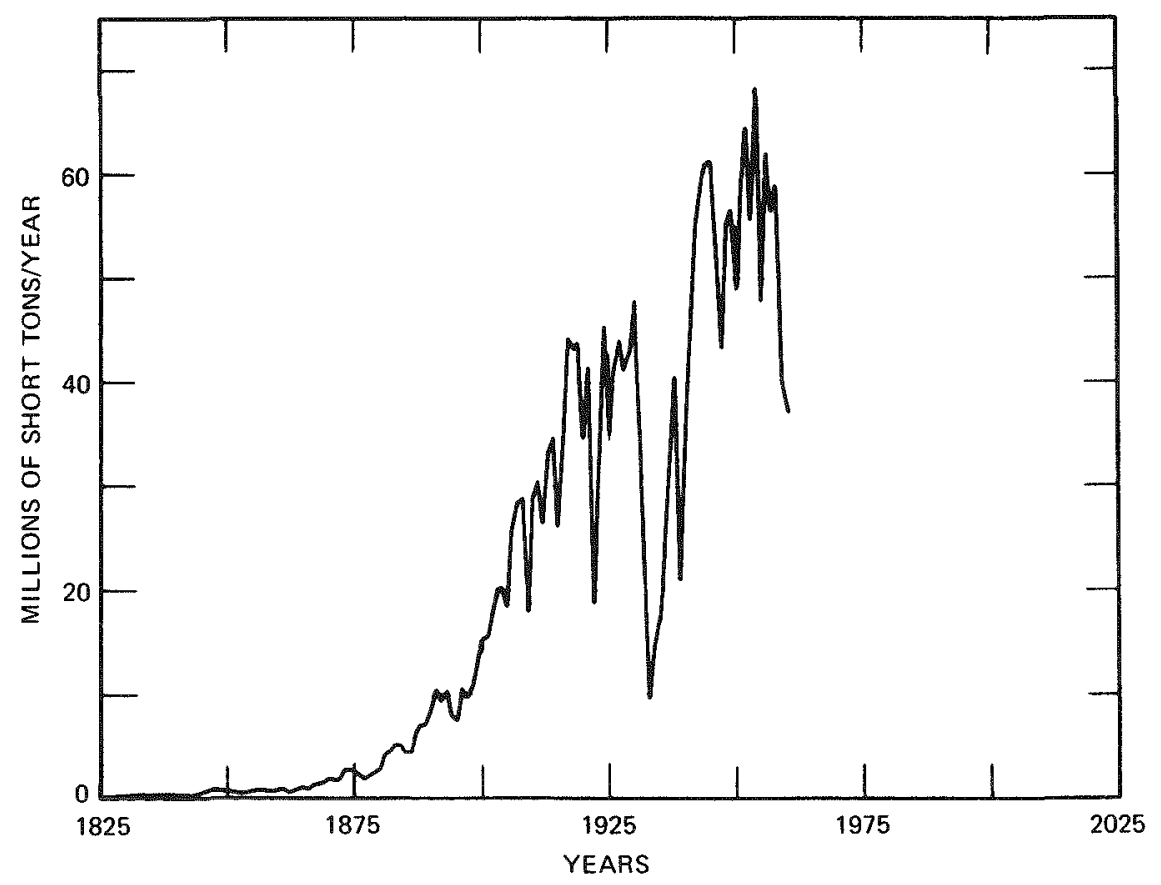

Fig. 28 U.S. production of pig iron, 1825-1958.

when production first reached a peak of 1.0 milhon short tons per year. Subsequently the production rate has oscillated rather widely but with a gradual incredse to d level dveraging about 1.7 million tons per year during the five-year period 1964-1968. Also, the United States made the transition from a net expoiter to a net importer of copper in 1941.

Figure 31 gives the annud U.S production of lead from 1825 to 1958 , and Fig. 32 that of zinc from 1880 to 1958 These two metals are closely associated geologically, and the ores of both are commonly produced from the same mines The peak rate of production for lead of about 680,000 short tons per yedr occurred in 1926. This was followed by a sharp decline which not even the requirements of World War II were able to reverse stgnificantly. The decline has continued unt1l, by the five-year period 1964-1968, the average annual production had descended to 320,000 tons per year. The transition from a net exporter to a net importer of lead was made by the United States in 1940

The annual production of zinc, as seen in Fig 32, reached two nearly equal peaks In 1926 and 1942 of 775,000 and 768,000 short tons per year, respectively Since 1942 the production rate has declined to an averdge of 567,000 tons per year during the five-year penod of 1964-1968. The transition from a net exporter to a net importer of zinc was made by the United States in 1943. 


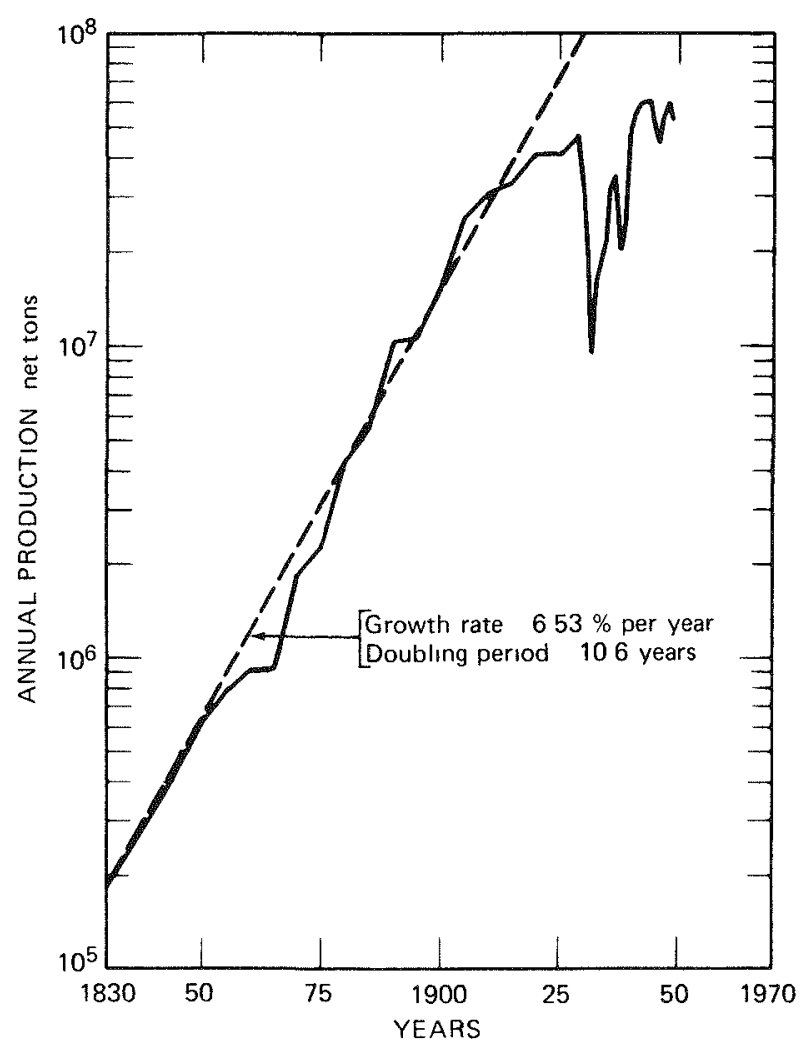

Fig. 29 U.S. production of pig uron, semilogarithmic scale.

While these are only individual examples, they serve to illustrate a basic principle ndmely, that the earth's initial accumulations of high grade ores of industrial metals are as exhdustrble as the initial deposits of the fossil fuels, and during comparable periods of time In New York, from Feb 27 to Mar 4, 1971, the American Institute of Mining, Metallurgical and Petroleum Engineers held its centennial celebration, during which broad-scale reviews were made of various aspects of the minerds industries With regard to the ore resources for the industrial metals, one of the recurrent themes touched upon by various speakers was essentially the following

With the exception of the ores of iron and aluminum for which the known reserves are probably adequate for a century or more, the known world reserves for most of the other industrial metals are probably sufficient to meet all requirements unt1 the end of the present century Beyond that, it is uncertain what may be done

A favonte rebuttal to this conclusion is that with enough energy metals may be extracted from rocks of lower and lower grade indefinitely Even if this should be 


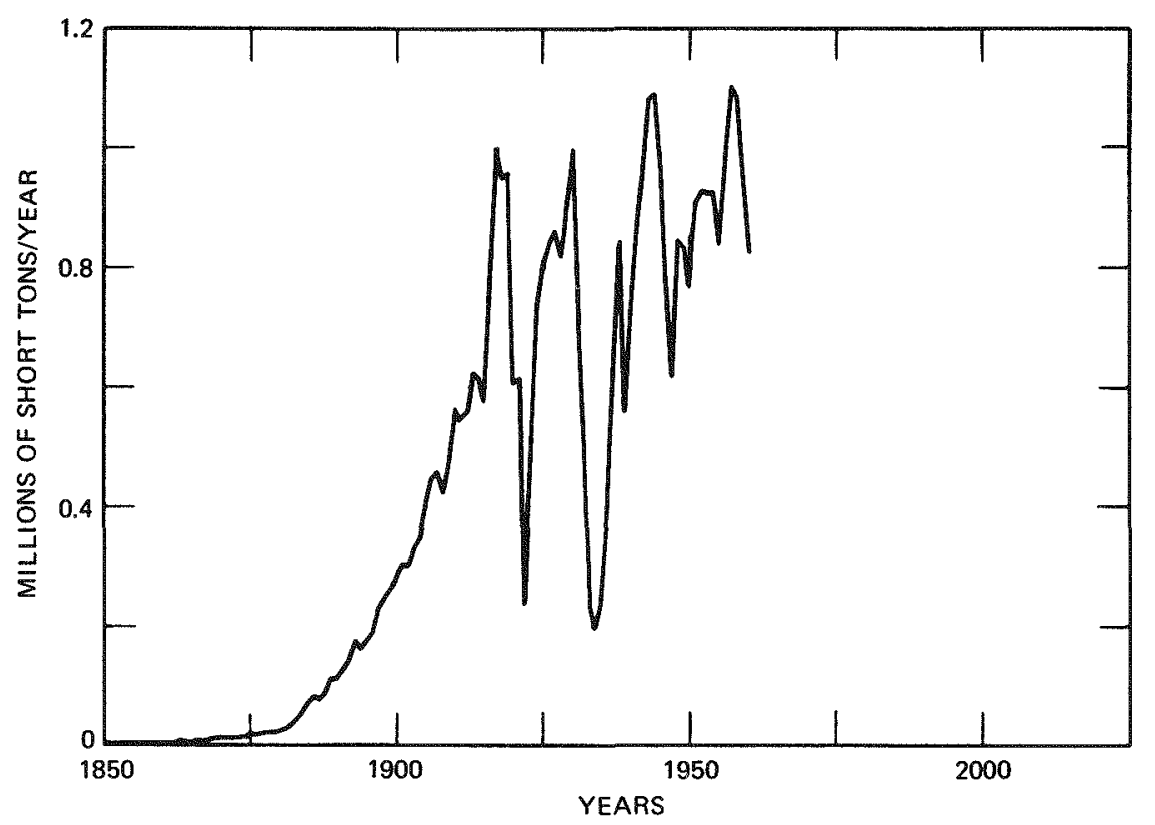

Fig. 30 U.S. production of copper, 1850-1958.

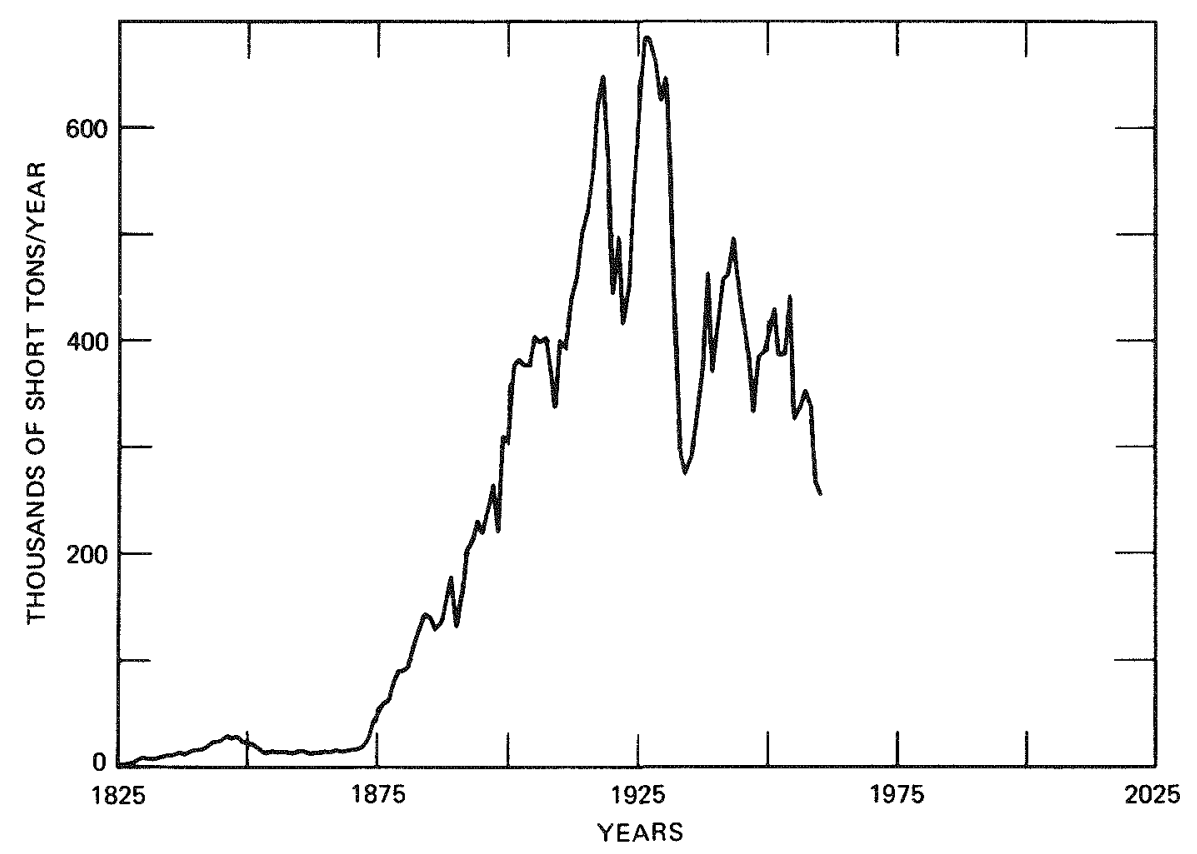

Fig. 31 U. S. production of lead, 1825-1958. 


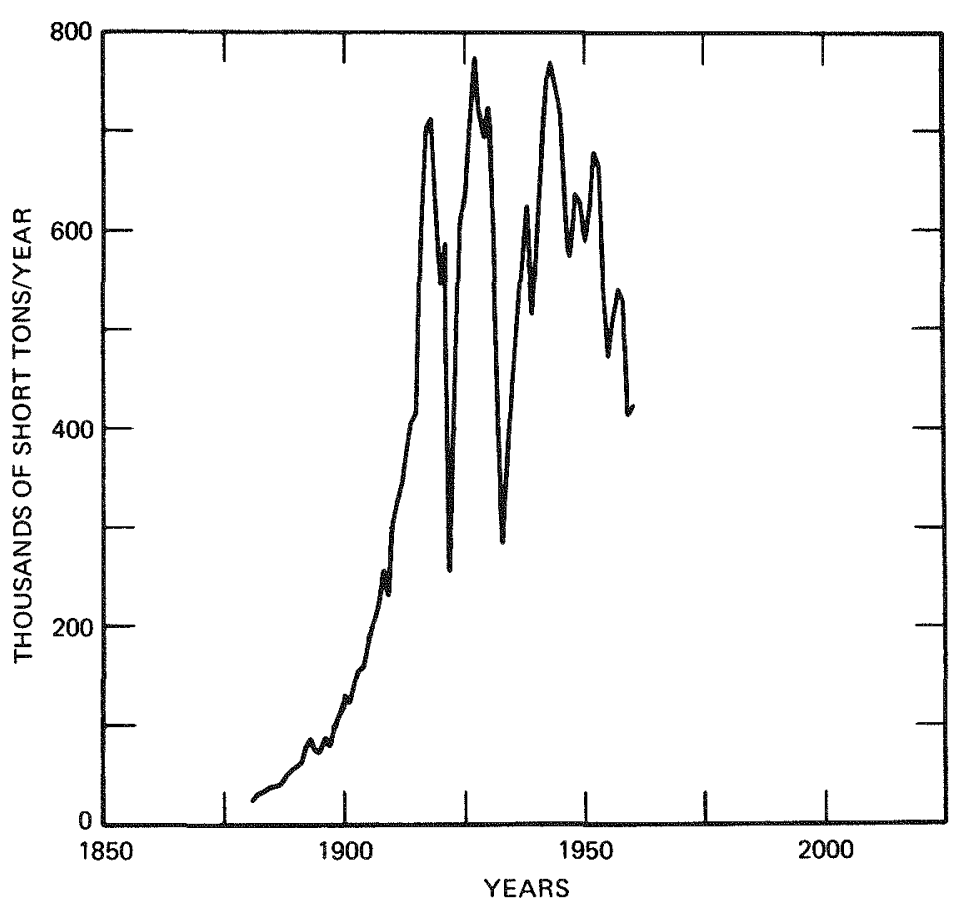

Fig. 32 U.S. production of zinc, 1880-1958.

physically posstble, such a procedure is rendered doubtful by ecological constraints not usually taken into account.

\section{PRINCIPLES OF ECOLOGY}

One of the consequences of the developments that we have just reviewed is that they have been the cause of one of the more severe ecological disturbances of the earth's plant and anımal populations in geological history. Let us therefore consider briefly some of the basic principles of ecology as a means of anticipating the constraints that these may impose upon future developments.

One of the first of these is the growth law of biologic populations. This may be stated in two parts. The first part is that the population of any biologic species from bacterid to elephants will, if given ample food supply and a favorable environment, increase exponentially or geometrically with time. A mathematical expression of this type of growth is given by the equation

$$
P=P_{0} 2^{t / T}
$$




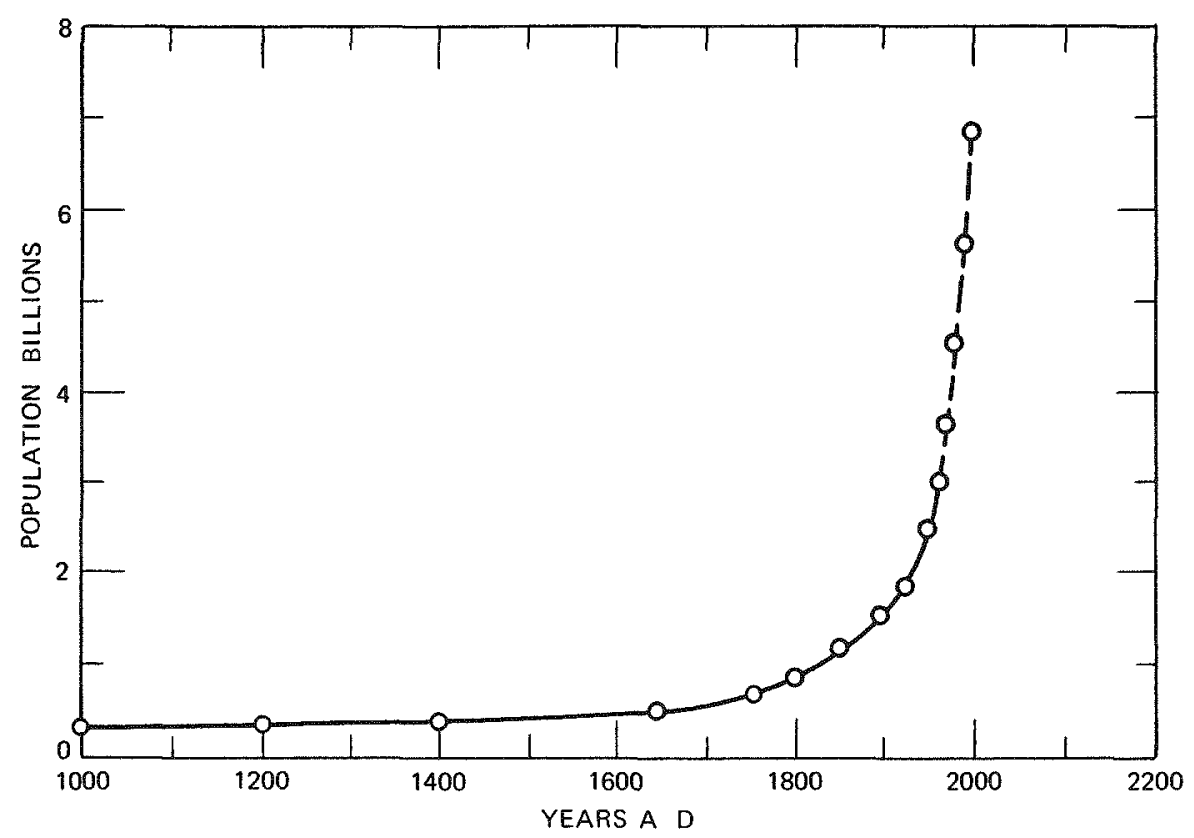

Fig. 33 Grow th of world human population sence 1000 A.D.'

Here $P_{0}$ is the initial population, $P$ is the population after a period of time $t$ and $T$ is the time required for the population to double Hence, $t / T$ represents the number of times the population doubles during the period $t$ of exponential growth

The growth of the world human population since the year $1000 \mathrm{~A} \mathrm{D}$, as shown graphically in Fig 33, is a qualitative example of this principle The human population has increased from roughly 300 million at the year 1000 to a present figure of 3600 million, and it is expected to reach about 7000 million by the year 2000 A D This would represent a 233 fold increase in 1000 years, or 454 doublings dunng that penod This increase has occurred in response to a better food supply, a better environment, and improved standards of health, made possible by the concurrent technological advances and continuously increasing utilization of energy The growth rate during this penod was not unform but accelerded with a corresponding shortening of the doubling period from close to 1000 years at $1000 \mathrm{AD}$ to a present figure of only 37 yedrs

Although this first principle of exponential growth was originally formulated for biologic populations, it is also valid for the growth of industrial activities We have noted dready how the production of coal, of orl and gas, and of the industrid metals edch increased exponentially for a century or more with doubling periods of from 8 to 16 yeas The growth of world electric power generating capacity, shown in Fig 34, is another major example Beginning at near $\iota$ ero in 1900, world electric power capacity had leached $900 \times 10^{9}$ watts by 1967 and is increasing dt d ate of $8 \%$ per year with a 


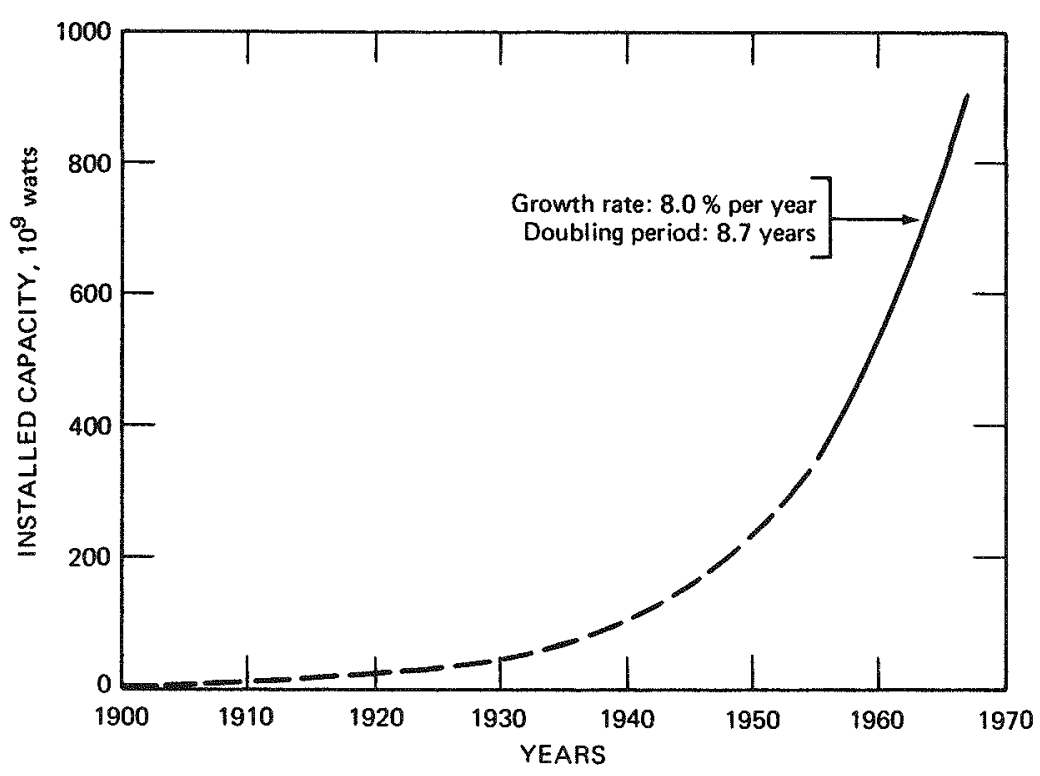

Fig. 34 Growth of world electric-power generating capacity. ${ }^{3}$

doubling period of but 8.7 years. Likewise, the world population of passenger automobiles is increasing at a rate of $6.69 \%$ per year with a doubling period of 10.4 years.

The second part of the law of growth is that the exponential phase can be sustained only for a temporary period of time or for at most a few tens of doublings. That this must be so can be demonstrated by elementary arithmetic. Consider, for example, the checkerboard problem of placing one grain of wheat on the first square, two on the second, four on the third, and doubling the number of grains for each successive square. The number of times the initial quantity of one grain will have been doubled by the time the last or $64 t h$ square is reached will be 63 times. Therefore the number of grains on the last square will be $2^{63}$. By volume this would amount to approximately 1000 times the world's present annual wheat crop. The same principles apply also to biological populations and to industrial activities, whether the production of mineral raw materials, of automobiles, or of electrical-power capacity. The earth itself cannot tolerate growth of such activities from small beginnings for more than a few tens of doublings.

The complete law of growth, including both the initial exponential phase and the leveling-off phase, is illustrated by the logistic growth curve shown in Fig. 35. An inverted form of this is represented when a biologic population encounters unfavorable conditions and decreases before leveling off to a lower equilibrium number.

A second ecologic principle is that in an ecological complex of plant and animal populations coexisting in any given region, if the population of any single species is 


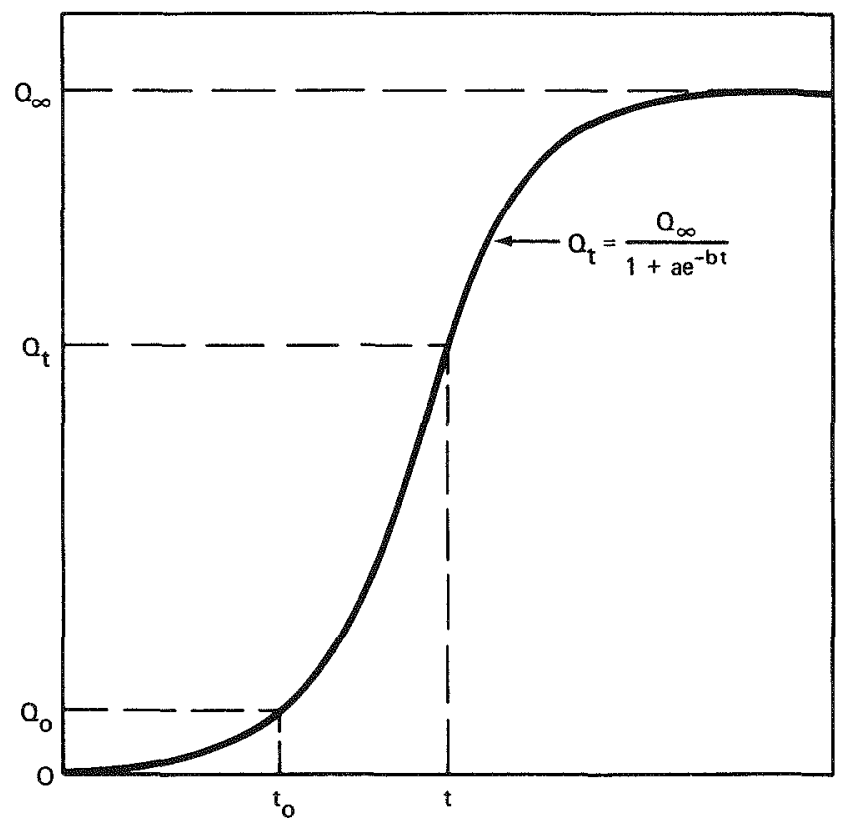

Fig. 35 Logistic growth curve showing both the exponential phase and the leveling-off phase of growth.

disturbed, those of all other species are affected. A simple example of this is the upset that sometimes occurs when an exotic species is introduced, as when European rabbits were introduced into Australia That this relationship also applies to an industrial complex is evident in the effect of the nse of motor vehicles on the populations of horses and buggies and of rallroad passenger trains. Another type of major disturbance is produced by seculdr climatic changes, such as from hot to cold or wet to dry.

Combining these several ecological principles with the known fact from paleontology that the time span for individual species is commonly measurable in millions of years leads to a very fundamental proposition namely, a rapid rate of population change, when averaged over a few years to avold seasonal variations, is a highly abnormal event, the normal state being one in which populations remain nearly stationary or else drift slowly with time. This can be shown for any given species by noting that the extreme range from the lowest to the highest population cannot involve as many as 100 doublings. If the species has existed for a millon yedrs and if this extreme change from the lowest to the highest occurred during this time, this would involve less than 100 doublings in a million years, or an average length of time per doubling of more than 10,000 years. Since populatıons, when disturbed, change with doubling times ranging from tens of minutes for bacteria to tens of years for large mammals, it follows that such periods of rapid change can only be of brief duration. 


\section{HUMAN AFFAIRS IN TIME PERSPECTIVE}

When man's conquest of energy and its associated technological culture is considered in conjunction with essential ecological constraints and on a time span of human history extending from 10,000 years in the past to 10,000 years in the future,
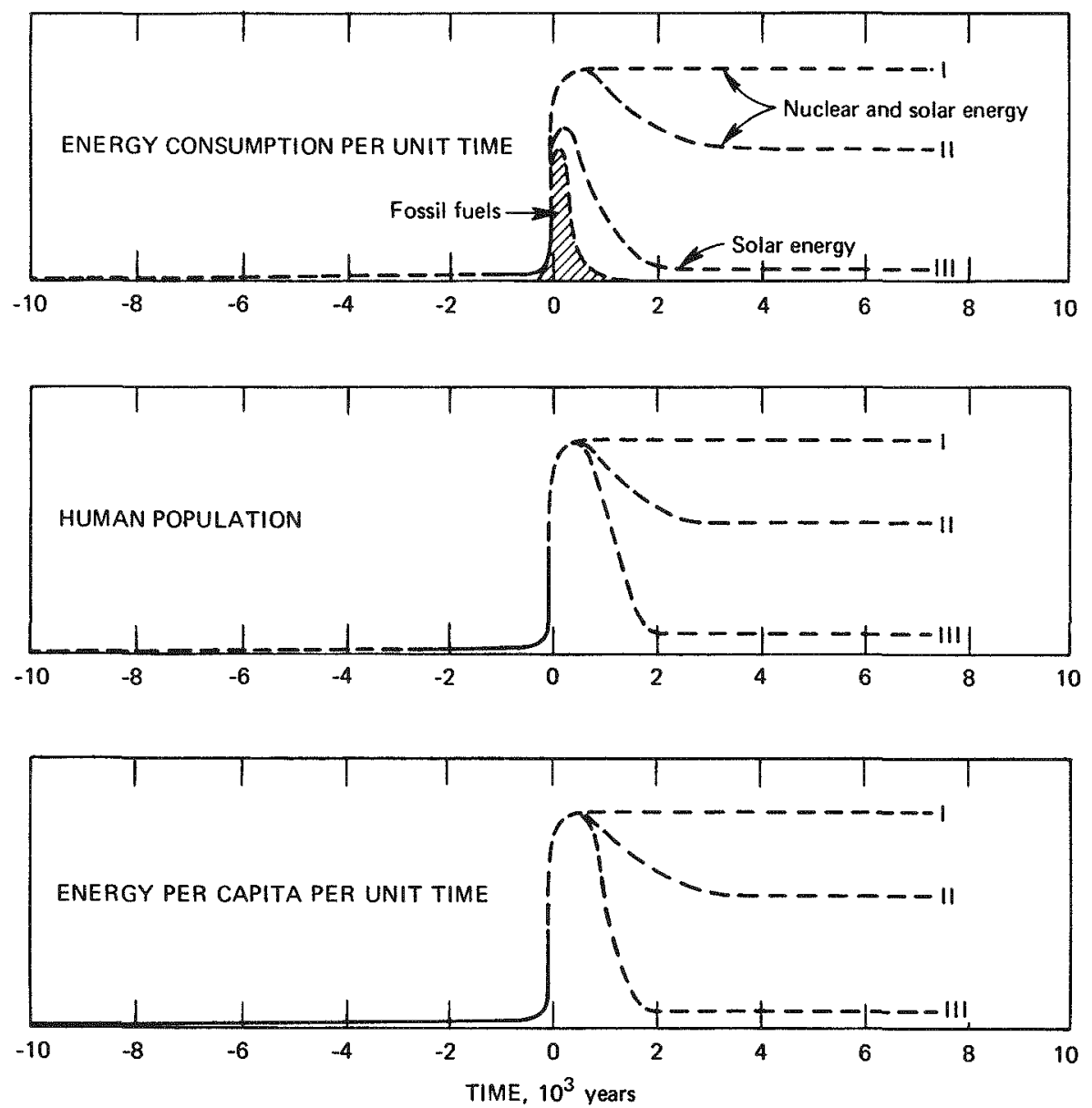

Fig. 36 Growth of human population and energy consumption viewed on a time scale from 10,000 years in the past to 10,000 years in the future. ${ }^{1}$

a much clearer picture of the nature of our present situation and problems emerges. On such a time scale, as is shown in Fig. 36, most of the major components of our present industrial civilization, including the human population, when plotted graphically would plot either near or at zero for all past history until the present is approached. Then in each instance the curve, after a short, barely perceptible rise, 
would turn sharply and almost vertically upward to its present magnitude However, because of the impossibility of any one of these curves continuing to increase for more than a small number of additional doublings, each curve, depending on its nature, must level off in one of three ways (1) as with water power, it could level off asymptotically to a maximum value that might be sustained for a long period of time, (2) it might overshoot and have to drop back and stabilize at a lower level more compatible with the earth's resources and ecological requirements, or (3) it might, as in the case of exhaustible resources or the extinction of a biologic species, decline to zero.

Because the rise of our technological society up to the present has been based principally upon the exploitation and exhaustion of an initial supply of fossil fuels and high-grade ores of metals and because the human population is alreddy seriously too large, it appears most improbable that the leveling-off process can be of the type asymptotic to a maximum as indicated by I in Fig 36 it is technologically and biologically feasible, however, to drop back and stabilize at an intermediate level, as indicated by II, which could be sustaned as a near steady state for possibly a millennium or longer Finally, there is also the possibility if not the probability that present trends of population growth and resource exhaustion could be continued to a catastrophic conclusion followed by a collapse of our technological culture and a return to the low-energy level of existence of our ancestors of only a few generations ago

Regdrdless of which of these courses may actually be followed, it is clear that the episode of exponential industral growth can be only a transitory epoch of about three centuries duration in the totality of human history It represents but a brief transitional interval between two very much longer periods, each characterized by rates of change so slow as to be regarded essentidly as a period of nongrowth Although the forthcoming penod poses no insuperable physical or biological difficulties, it can hardly fall to force d revision of those aspects of our present exponential-growth culture which lead us to contemplate a state of nongrowth as being either unthinkable or intolerable

\section{REFERENCES}

1 M. King Hubbert, Energy Resources, National Academy of Sciences-National Research Counc1, Publication 1000-D, 1962

2 _. Energy Resources, in Resources and Man Chap 8, pp 157-242, National Academy of Sciences Publication 1703, W H Freeman and Company, San Francisco, 1969

3 _. Energy Resources for Power Production, in Environmental Aspects of Nuclear Power Stations, Symposium Proceedings, New York, August 1970, pp. 14-43, International A tomic Energy Agency, Vienna, 1971 (STI/PUB/261)

4. Paul Averitt, Coal Resources of the United States, January 1, 1967, U S Geological Survey, Bulletın 1275, 1969 
5. A. D. Zapp, U. S. Geological Survey, Domestic and World Resources of Fossil Fuels, preliminary reports for the National Resources Subcommittee of the Federal Council of Scrence and Technology, Nov. 28, 1961, unpublished.

6. - Future Petroleum Productng Capactty of the Unted States U. S. Geological Survey Bulletin 1142-H, 1962.

7. Potential Gas Committee, Potential Supply of Natural Gas in the United States as of Dec. 31, 1966, 1967.

8. $\ldots$, Potential Supply of Natural Gas in the Unted States as of Dec. 31, 1968,

9. J. H. Smith, Geothermal Energy in New Zealand, paper prepared for presentation at the United Nations Symposium on the Development and Utilization of Geothermal Resources, P1sa, 1970.

10. Donald F. White, Geothermal Energy U. S. Geological Survey, Circuldr 519, 1965.

11. U. S. Atomic Energy Commission, Annual Report to Congress of the Atomic Energy Commission for 1970.

12. V. E. Swanson, O1l Yield and Uranium Content of Black Shales, in Urantum and Carbonaceous Rocks, U. S. Geological Survey, Professional Paper 356, 356A, pp. 1-44, 1960.

13. David J. Rose, Controlled Nuclear Fusion Status and Outlook, Science, 172(3985) 797-807 (1971).

14 D F Hewett, Cycles in Metal Production, American Institute of Mining and Metallurgical Engineers, Technical Paper 183, pp. 65-98, 1929. 